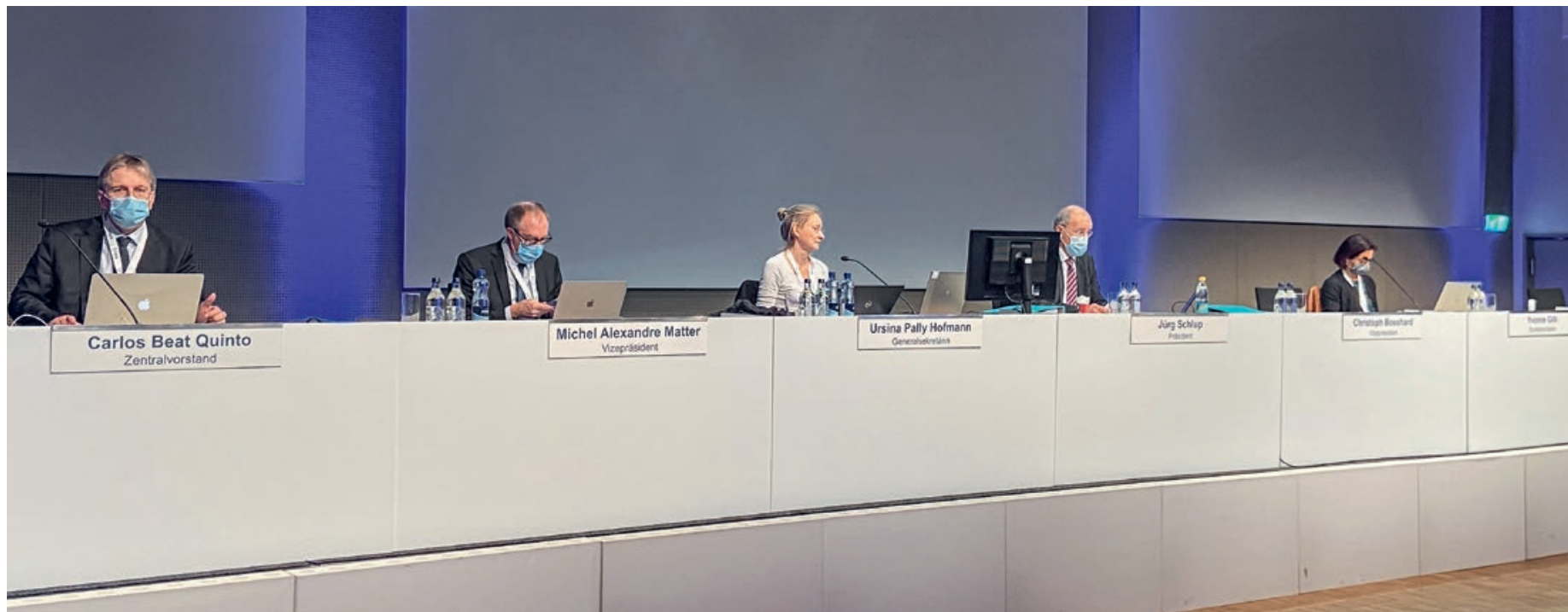

Die diesjährige Ärztekammer findet aufgrund der Corona-Pandemie virtuell statt. Nur einige wenige Mitarbeitende der FMH, die Generalsekretärin und die Zentralvorstandsmitglieder befinden sich vor Ort auf dem BERNEXPO-Gelände. Auf dem Bild fehlt unter anderem das abtretende ZV-Mitglied Jürg Unger. Er nimmt virtuell an der Ärztekammer teil.

\title{
Beschlussprotokoll der ersten und zweiten Arztekammer 2020
}

\section{Nicole Furgler}

Leiterin Abteilung Zentrales Sekretariat

Anmerkung der Protokollführerin: Aus Gründen der Lesbarkeit werden die Traktanden nach Massgabe der Nummerierung und nicht in der Reihenfolge der Diskussion aufgeführt. Am Ende des Beitrags befindet sich ein Glossar der verwendeten Abkürzungen.

\section{Mittwoch, 28. Oktober 2020}

\section{Begrüssung und Mitteilungen}

Nach Erreichen des Quorums eröffnet Dr. med. Jürg Schlup / Präsident FMH die zweitägige ÄK 2020. Er heisst alle Delegierten herzlich willkommen.

Dr. iur. Ursina Pally Hofmann / Generalsekretärin FMH und Leiterin Rechtsdienst hält rückblickend fest, dass am Freitagabend, 23. Oktober 2020 die Berner Regierung aufgrund der aktuellen Covid-Situation Veranstaltungen mit mehr als 15 Personen bis auf Weiteres verboten hat. Daher hat der Zentralvorstand der FMH am gleichen Abend beschlossen, einerseits die ÄK virtuell als Zoom-Videokonferenz durchzuführen und andererseits die Gäste auszuladen. Diese Mitteilung wurde allen Delegierten um 23.20 Uhr per Mail zugestellt. Am darauffolgenden Sonntag wurden die Dele- gierten nochmals angeschrieben, unter anderem mit dem Hinweis, dem zentralen Sekretariat bis Montagmittag ihre Teilnahme zu bestätigen. Aufgrund dieser Teilnahmebestätigungen wurden am Montagabend den stimmberechtigten Delegierten die Zugangscodes zur Zoom-Videokonferenz per A-Post und eingeschrieben zugestellt. Am Dienstag wurden die Delegierten mit den technischen Anweisungen zum Login, zur Eingangskontrolle und mit weiteren Informationen versorgt und auch mit dem Link zur Übungssitzung bedient. Diese Übungssitzung hat stattgefunden.

Die antrags- und mitspracheberechtigten Delegierten können via Stream teilnehmen, dies aus Sicherheitsgründen, weil in der Zoom-Sitzung die Wahlen und Abstimmungen abgehalten werden. Ihre Wortmeldungen können sie via die Mailadresse aerztekammer[at]fmh ch zustellen. Diese werden dann verlesen. Ursina Pally Hofmann / Generalsekretärin FMH und Leiterin Rechtsdienst erklärt das Vorgehen bei Störungen und Problemen und weist auf die Hotline hin. Für die Anwesenden vor Ort gilt ein Schutzkonzept, welches eingehalten werden muss.

Ursina Pally Hofmann / Generalsekretärin FMH und Leiterin Rechtsdienst macht die weiteren üblichen organi- 


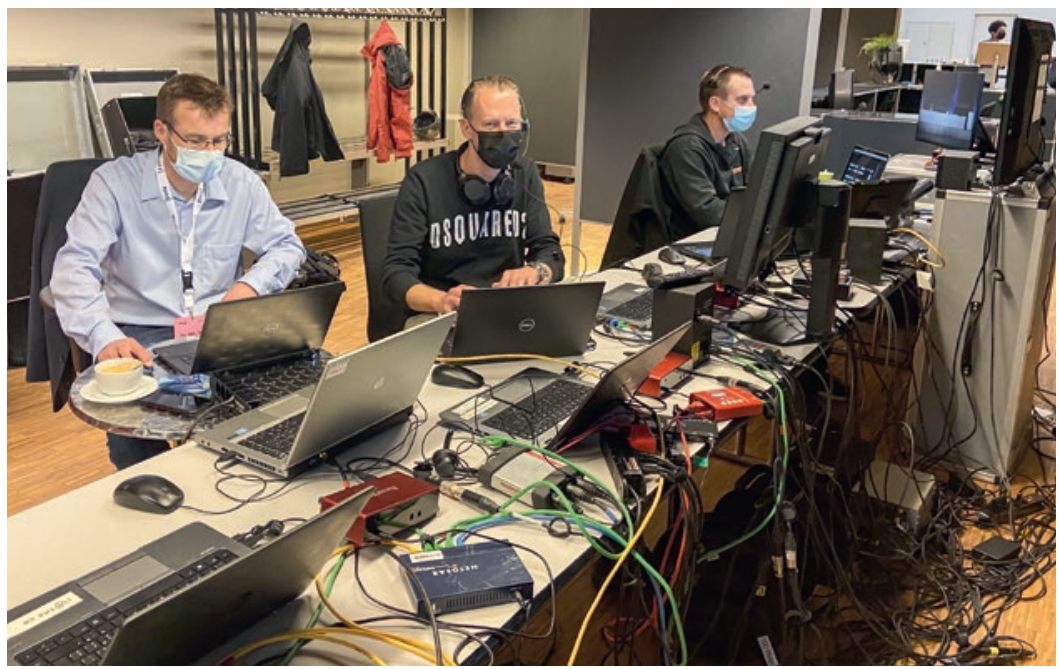

Viel Kabel wird benötigt für die technische Übertragung der virtuellen Ärztekammer. Links, Nils Graf aus dem Rechtsdienst, zuständig für die korrekte Durchführung der zahlreichen Abstimmungen. In der Mitte Dominik Kreuter, Leiter der Abteilung ICT und technischer Kopf der virtuellen Ärztekammer. Rechts ein externer Techniker.

satorischen Mitteilungen und weist darauf hin, dass alle zusätzlichen Sitzungsunterlagen, welche üblicherweise in Form einer Dokumentenmappe abgegeben werden, auf myFMH zu finden sind.

Jürg Schlup / Präsident FMH informiert, dass ausser Jürg Unger, der sich in Quarantäne befindet, alle Vorstandsmitglieder zusammen mit der Generalsekretärin vor Ort sind. An dieser Stelle bedankt er sich ganz herzlich bei allen involvierten Mitarbeitenden der FMH und insbesondere bei der ICT-Abteilung unter Dominik Kreuter, beim Rechtsdienst unter Ursina Pally, beim Zentralsekretariat unter Nicole Furgler und bei der Kommunikation unter Charlotte Schweizer für deren Sondereffort zur Durchführung dieser sehr kurzfristig zur virtuellen ÄK umorganisierten Sitzung.

Die Sitzung beginnt mit einer Probeabstimmung und anschliessend wird das Büro bestellt. Dieses besteht aus dem Präsidenten, den Vizepräsidenten und der Generalsekretärin. Julien Duruz / Rechtsdienst FMH und Dominik Kreuter / Abteilungsleiter ICT bilden die Co-Leitung des Wahlbüros; Anne-Sylvie Thiébaud / Verantwortliche für die FMH-Standeskommission unterstützt diese als Stellvertreterin. Als Stimmenzähler schlägt Jürg Schlup / Präsident FMH Dr. Rudolf Ott, Standeskommission ÄG BL, und Dr. iur. Caroline Hartmann, Rechtsdienst FMH, vor.

Aufgrund technischer Probleme bei einigen Delegierten anlässlich mehrerer Probeabstimmungen stellt Jürg Schlup / Präsident FMH den folgenden

Ordnungsantrag:

Sofern nicht mehr als zwei Delegierte ein technisches Problem haben, sind die Abstimmungen/Wahlen gültig.

\section{Beschluss:}

Der Antrag wird mit 163 Ja, 7 Nein und 3 Enthaltungen angenommen.

\author{
Stimmenzählende \\ Antrag: \\ Genehmigung der Stimmenzählenden \\ Beschluss:
}

Die Stimmenzählenden werden mit 162 Ja, 0 Nein und 1 Enthaltung gewählt.

Traktandenliste

Antrag:

Genehmigung der Traktandenliste, die beide Tage umfasst.

Beschluss:

Die Traktandenliste wird mit 167 Ja und 1 Nein genehmigt.

Gemäss Art. 11, Abs. 3 GO legt die ÄK zu Beginn jeder Sitzung den Zeitpunkt fest, nach dessen Ablauf weder Beschlüsse gefasst noch Wahlen vollzogen werden dürfen. Der Präsident schlägt als Tagungsende 18.30 Uhr vor.

Antrag Festlegung Tagungsende:

Als Tagungsende wird 18.30 Uhr festgelegt. Nach 18.30 Uhr dürfen weder Beschlüsse gefasst noch Wahlen vollzogen werden.

Beschluss:

Der Antrag wird mit 148 Ja, 13 Nein und 6 Enthaltungen angenommen.

Ordnungsantrag-Redezeitbeschränkung: Für die Behandlung der Traktanden der heutigen ÄK gilt eine Redezeitbeschränkung von zwei Minuten für Einzelredner. Keine Beschränkung gilt für den Präsidenten oder seinen Stellvertreter der jeweiligen stimm- oder antragsberechtigten Ärzteorganisation sowie für den Sprecher des ZV.

Beschluss:

Der Antrag wird mit 162 Ja, 4 Nein und 1 Enthaltung angenommen.

Jürg Schlup / Präsident FMH weist die Delegierten darauf hin, dass gemäss Art. 11, Abs. 5 der GO FMH jeder Delegierte, jedes ZV-Mitglied und der Generalsekretär das Recht haben, Anträge zu den zur Diskussion stehenden Traktanden zu stellen. Anträge sind dem Vorsitzenden schriftlich vor oder während der Sitzung einzureichen

\subsection{Einführung des Präsidenten}

1.2. Legislaturbericht

Jürg Schlup / Präsident FMH beginnt sein Referat mit folgendem Aufruf: Heute vertreten Sie hier nicht allein 
die rund 90 der FMH angeschlossenen Ärzteorganisationen, Sie vertreten hier auch die 38000 berufstätigen Ärztinnen und Ärzte in der Schweiz. Unsere Mitglieder schauen auf Sie, unsere Mitglieder hoffen auf Sie. Nehmen Sie diese Vertretung unserer Mitglieder und des corps médical in diesem Land heute und morgen verantwortungsvoll wahr. Unsere Mitglieder sind Ihnen dankbar dafür.

Jürg Schlup / Präsident FMH hält Rückblick über die Legislatur 2016-2020.

- Ihren Auftrag, das Budget zu stabilisieren, hat der Zentralvorstand umgesetzt und von den aufgetragenen 5,8 Mio. Mitgliederfranken insgesamt CHF 5,5 Mio. eingespart.

- In den letzten 12 Monaten hat die FMH im Namen der Ärzteschaft

- 320 Medienanfragen beantwortet, d.h. eine bis zwei pro Tag;

- 24 Medienmitteilungen publiziert, d.h. zwei pro Monat

- und 444 Tweets abgesetzt, d.h. zwei pro Tag.

- Die FMH berät jede Woche zwei bis drei Dutzend unserer Mitglieder.

- Der Zentralvorstand hat die politische Interessenvertretung verstärkt und deren Wirksamkeit erhöht. Dies zeigte sich v.a. in den letzten drei Jahren bei der Bekämpfung des Globalbudgets und bei der Finalisierung der Zulassungssteuerung.

- Nach der Ablehnung der Tarifrevision in der Urabstimmung zu Legislaturbeginn 2016 ist es dem Zentralvorstand zusammen mit dem Gremium Cockpit unter der Leitung von Urs Stoffel gelungen, eine neue Tarifrevision einzureichen. Damit ist die Ärzteschaft der mit der Urabstimmung 2016 verlorenen Tarifautonomie wieder einen grossen Schritt nähergekommen.

Jürg Schlup / Präsident FMH kommt nun zu den Aktualitäten.

- Der Zentralvorstand hat besonders in den letzten acht Monaten - Corona-bedingt - seine Arbeitskadenz noch massiv erhöht, und er hat allein in diesem Jahr bislang 62 protokollierte Sitzungen abgehalten. Dabei waren ausserordentliche Zusatzleistungen gefragt im Bereich eHealth-Digitalisierung unter der Leitung von Yvonne Gilli, von Carlos Quinto im Bereich Public Health und von Christoph Bosshard im Zusammenhang mit der 11-Mio-Gesamtsanierung Elfenstrasse sowie im Generalsekretariat unter Ursina Pally mit dem Covid-gesicherten Umzug des Generalsekretariates und schliesslich im Bereich Kommunikation. Allen gebührt ein grosses Dankeschön zum Abschluss dieser Legislatur!

- Jürg Schlup / Präsident FMH zeigt sich - im Zusammenhang mit der Corona-Pandemie - zuversicht- lich, dass auch die Herausforderungen des bevorstehenden Winters gemeistert werden. Die Vehemenz, mit der von Teilen der Bevölkerung Unsicherheiten oft zurückgewiesen werden, in Erwartung sicherer Anweisungen, deutet auf ein realitätsfremdes Bild der Wissenschaft hin. Denn Wissenschaft ist eben keine Sammlung widerspruchsfreier Fakten. Erkenntnis und Fortschritt werden erst durch Unsicherheit und auch durch Widersprüche ermöglicht. Diese Unsicherheiten auszuhalten wird eine wichtige Herausforderung der nächsten Zeit sein.

- Der Antrag der europäischen Pharmaunternehmen an die Europäische Kommission auf Haftungsbefreiung bei Covid-19-Impfstoff-Anwendungen lässt auf schwerwiegende Selbstzweifel und Sicherheitsbedenken dieser Hersteller schliessen.

- Covid-19-induzierte Umsatzausfälle und Mehrkosten können sich im Gesamtjahr auf schätzungsweise sechs bis zehn Prozent des Gesamtvolumens des Vorjahres belaufen und fallen bislang anteilmässig stärker im praxis-ambulanten Bereich ins Gewicht als im spital-ambulanten und im stationären Versorgungssektor. Seit März führt die FMH Gespräche mit dem BAG, aber das Departement des Innern ist weiterhin allein in Härtefällen bereit, Ausfälle oder Mehrkosten zu entschädigen. Es muss davon ausgegangen werden, dass betroffene Praxen und Spitäler mit Kostenreduktionen werden reagieren müssen.

- Die Prämienentwicklung 2016-2021 beträgt +2,45\% pro Jahr; das ist keine Prämienexplosion! Hingegen stiegen die Reserven pro Versicherten in dieser Zeitperiode um 12\% pro Jahr: Das ist eine Reservenexplosion. Im letzten Jahr ging knapp ein Drittel der bezahlten Prämien in die Reserven. Gemäss dem Krankenversicherungsaufsichtsgesetz hätte das Bundesamt für Gesundheit, BAG, die übermässige Reservebildung in den vergangenen Jahren als Aufsichts- und Genehmigungsbehörde für Reserven und Prämien verhindern können.

- Gemäss unserer Mitgliederbefragung sind die wichtigsten drei Herausforderungen für die FMH aus einem guten Dutzend folgende:

- Mit einer starken (politischen) Vertretung der Ärzteschaft Gehör verschaffen

- Der Erhalt der Tarifautonomie

- Die Arbeitsbedingungen und Attraktivität des Arztberufes

- Beim Globalbudget geht es heute vor allem um folgende drei Themen:

- Kostendämpfung Paket 1 (seit Januar 2020 im Parlament) 


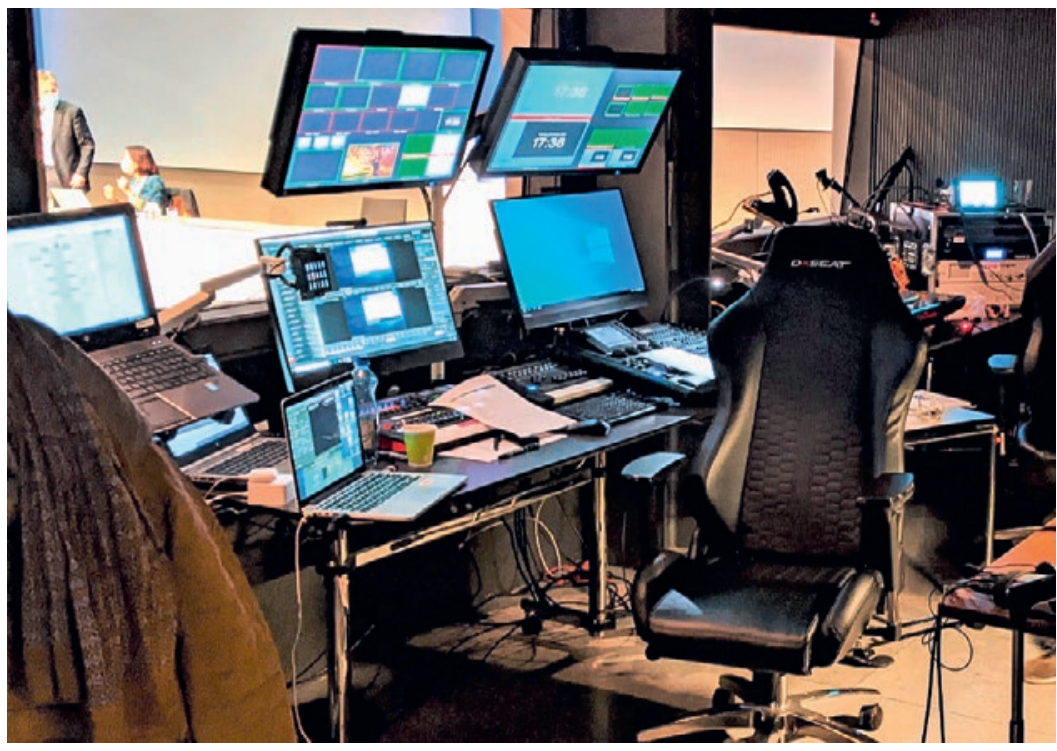

Blick hinter die Kulissen. winnen, gemeinsam ein Globalbudget zu verhindern und gemeinsam die Weiter- und Fortbildung zu gestalten sowie gemeinsam für einen attraktiven Arztberuf zu kämpfen.

\section{Gesamterneuerungswahlen Legislatur 2020-2024}

Die Gesamterneuerungswahlen werden mit einer elektronisch durchgeführten Probewahl begonnen, die erfolgreich ist.

\subsection{Wahl Präsidentin/Präsident SIWF}

Jürg Hafner / Präsident Findungskommission SIWF berichtet über das Auswahlverfahren. Nach Sichtung der vierzehn sehr gut qualifizierten Bewerbungsdossiers wurden die fünf bestqualifizierten Kandidatinnen und Kandidaten zu einem Interview eingeladen; schliesslich hat die Findungskommission daraus die zwei verbleibenden Kandidatinnen Monika Brodmann und

- CVP-Kostenbegrenzungsinitiative (im März 2020 eingereicht)

- Kostendämpfungspaket 2 (seit August 2020 in Vernehmlassung)

- Jürg Schlup / Präsident FMH weist auf eine Auftragsstudie des BAG hin, publiziert am 3.7.2019, welche zum Schluss kommt, dass degressive Tarife, Zielvorgaben und Rückforderungen eine dem Globalbudget vergleichbare Wirkung haben. Und weiter, dass ein dämpfender Effekt eines Globalbudgets oder vergleichbarer Massnahmen auf das Ausgabenwachstum empirisch nicht bestätigt werden kann.

- Im parlamentarischen Prozess hat die FMH darauf hingewiesen, dass Zielvorgaben gegen das Versicherungsprinzip verstossen, weil der Versicherungsanspruch dadurch eingeschränkt wird.

Jürg Schlup / Präsident FMH weist darauf hin, dass die Ärzteschaft sich durch politische Vorstösse schnell emotionalisieren lässt, statt rational analysierend und vorausschauend, mit Blick auf langfristige Erfolge zu handeln. Das nützt die Politik brutal aus zum divide et impera. Es spielt politischen Gegnern in die Hände, wenn Teile der Ärzteschaft alleine ihre ganz individuelle Berechnung machen. Es spielt politischen Gegnern auch in die Hände, wenn einige Ärztegruppen öffentlich andere Ärztegruppen kritisieren. Ärztinnen und Ärzte müssen zusammenstehen und dürfen sich nicht individualisiert verzetteln. Sie müssen für übergeordnete Interessen der gesamten Ärzteschaft einstehen und aufzeigen, warum diese für unser Gesundheitswesen wichtig sind. Es gilt, sich auf gemeinsame Prioritäten zu einigen und die Tarifautonomie zurückzuge-
Nathalie Koch für die Wahl vorgeschlagen.

Aldo Kramis / Präsident VEDAG und Präsident der Ärztegesellschaft des Kantons Luzern moniert im Namen der Dachverbände VEDAG, SMSR und OMCT, dass man sich in einer Zeit der Überregulierung eine Person als Präsident/in wünscht, die Gegensteuer geben kann und welche die Sorgen und Nöte der niedergelassenen Ärztinnen und Ärzte gut kennt. Zudem brauche es für dieses Amt eine standespolitisch bewährte Persönlichkeit. Die drei Dachverbände haben am Vortag zur ÄK ein Schreiben an alle Delegierten versandt, in welchem sie eine dritte Kandidatur in der Person von Christoph Bosshard, Vizepräsident der FMH, vorschlagen.

Zur Wahl stellen sich folgende Kandidierenden - BRODMANN MÄDER Monika Maria, 1962, Interlaken

- KOCH Nathalie, 1971, Lausanne

- BOSSHARD Christoph, 1964, Bern

Wahlresultat 1. Wahlgang

Gültige Stimmzettel 158; absolutes Mehr 80

Es haben Stimmen erhalten

- BRODMANN MÄDER Monika Maria

- BOSSHARD Christoph

- KOCH Nathalie

Nathalie Koch zieht sich für den 2. Wahlgang zurück.

Wahlresultat 2. Wahlgang

Gültige Stimmzettel 165; absolutes Mehr 83

Es haben Stimmen erhalten

- BRODMANN MÄDER Monika Maria

- BOSSHARD Christoph

Monika Brodmann wird mit 90 Stimmen zur neuen Präsidentin SIWF gewählt.

Jürg Schlup / Präsident FMH gratuliert Monika Brodmann zu ihrer Wahl. 


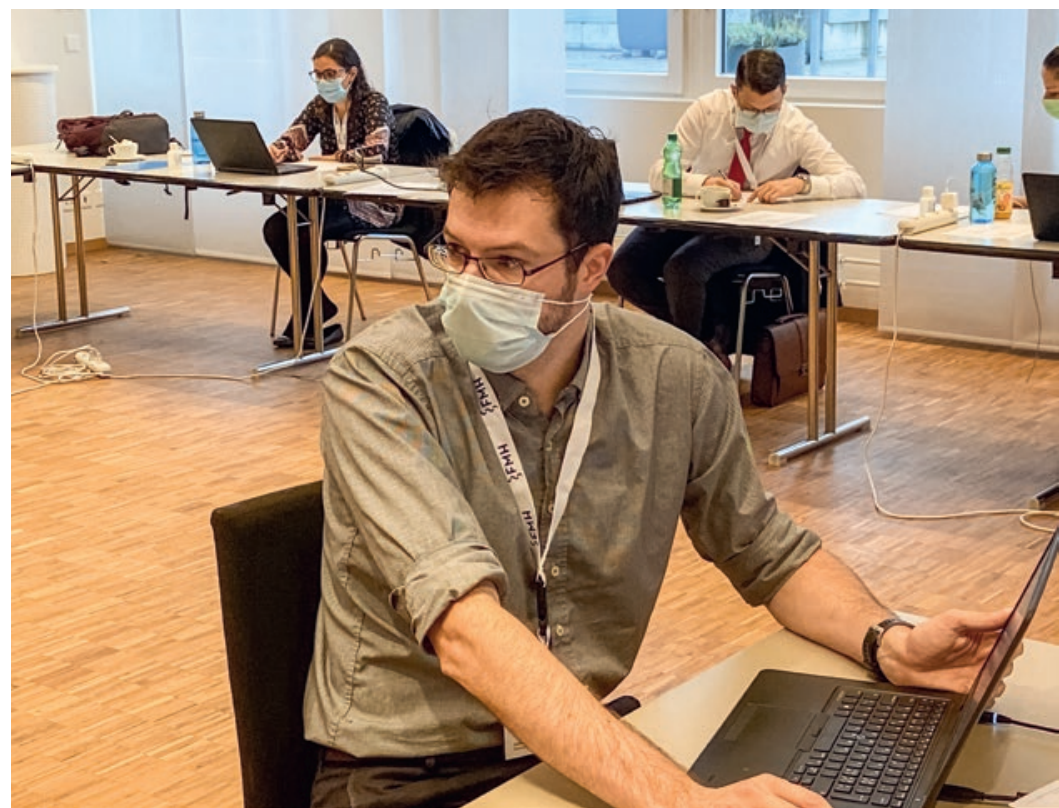

Das Wahlbüro unter der Leitung von Julien Duruz. Er sorgt gemeinsam mit Anne-Sylvie Thiébaud und den Stimmenzählerinnen und Stimmenzählern für die korrekte Durchführung der Gesamterneuerungswahlen des Zentralvorstandes und der Standeskommission.
1 Dieser Antrag geht am Folgetag ein und kommt dann zur Abstimmung 2 Dieser Antrag geht am Folgetag ein und komm dann zur Abstimmung.
Antrag:

Die ÄK beschliesst den Antrag des Vorsitzenden auf Wunsch der neu gewählten Präsidentin des SIWF, die Frist für die Amtsübernahme der neu gewählten Präsidentin bis zum 1. Februar 2021 zu verlängern.

Beschluss:

Die Amtsübernahme der neuen Präsidentin des SIWF ab 1. Februar 2021 wird mit 104 Ja, 11 Nein und 3 Enthaltungen bewilligt ${ }^{1}$.

\subsection{Wahl Zentralvorstand FMH}

Mit der Wahl entscheidet die ÄK auch darüber, die Altersgrenze für jene Kandidierenden hinauszuschieben, die während der Legislatur die Altersgrenze (gemäss Art. 22 der FMH Statuten) erreichen oder überschreiten.*

Zur Wahl stellen sich folgende Kandidierenden (in alphabetischer Reihenfolge)

- BOSSHARD Christoph, 1964, Bern (bisher)

- GILLI Yvonne, 1957, Wil SG (bisher)

- JUNG Tarzis, 1957, Meilen

- LEHKY HAGEN Monique, 1971, Glis

- MATTER Michel Alexandre, 1964, Genf (bisher)

- QUINTO Carlos Beat, 1966, Basel (bisher)

- SIROKA Jana, 1972, Münchenstein

- STOFFEL Urs, 1952, Kilchberg ZH (bisher)*

- ZIMMER Alexander, 1961, Solothurn

Wahlresultat 1. Wahlgang

Gültige Stimmzettel 150; absolutes Mehr 76
Gewählt als ZV-Mitglieder sind

- BOSSHARD Christoph 137

- SIROKA Jana 110

- STOFFEL URS 108

- GILLI Yvonne 107

- QUINTO Carlos Beat 96

- MATTER Michel Alexandre 89

- ZIMMER Alexander 76

Zusätzlich haben Stimmen erhalten

- LEHKY HAGEN Monique 57

- JUNG Tarzis 44

\subsection{Wahl Präsidentin/Präsident FMH}

Nach einer kurzen Besprechung beschliesst der ZV einstimmig, Yvonne Gilli als Präsidentin der FMH vorzuschlagen.

Wahlresultat 1. Wahlgang

Gültige Stimmzettel 163; absolutes Mehr 82

Es haben Stimmen erhalten

- GILLI Yvonne

- BOSSHARD Christoph

- MATTER Michel Alexandre

- STOFFEL Urs

- SIROKA Jana

Yvonne Gilli wird mit 123 Stimmen zur neuen Präsidentin FMH gewählt.

Antrag:

Die ÄK beschliesst den Antrag des Vorsitzenden auf Wunsch der neu gewählten Präsidentin der FMH, die Frist für die Amtsübernahme der neu gewählten Präsidentin bis zum 1. Februar 2021 zu verlängern.

Beschluss:

Die Amtsübernahme der neuen Präsidentin der FMH ab 1. Februar 2021 wird mit $132 \mathrm{Ja}, 11$ Nein und 3 Enthaltungen bewilligt ${ }^{2}$.

Jürg Schlup / Präsident FMH gratuliert Yvonne Gilli zu dieser ehrenvollen Wahl und macht die Delegierten darauf aufmerksam, dass sie als mehrheitliches Männergremium nun erstmals in der 119-jährigen Geschichte der FMH eine Kollegin als Präsidentin gewählt haben.

Yvonne Gilli / neu gewählte Präsidentin FMH bedankt sich auf Deutsch, Französisch und Italienisch bei den ÄK-Delegierten für das anerkennende Resultat und die Zusammensetzung im neu gewählten ZV, in welchem sie die Frauenquote um 100 Prozent gesteigert haben. Sie wertet dies als Signal an die kommende Ärztegeneration, insbesondere an die Ärztinnen, die bereits heute die Mehrheit unter der Ärzteschaft stellen. Es ist auch ein sehr fortschrittliches Zeichen im Kontext der europäischen Ärztekammern. Für einmal ist nämlich die Schweiz nicht das letzte Land, das eine Frau ins Präsidium wählt. 


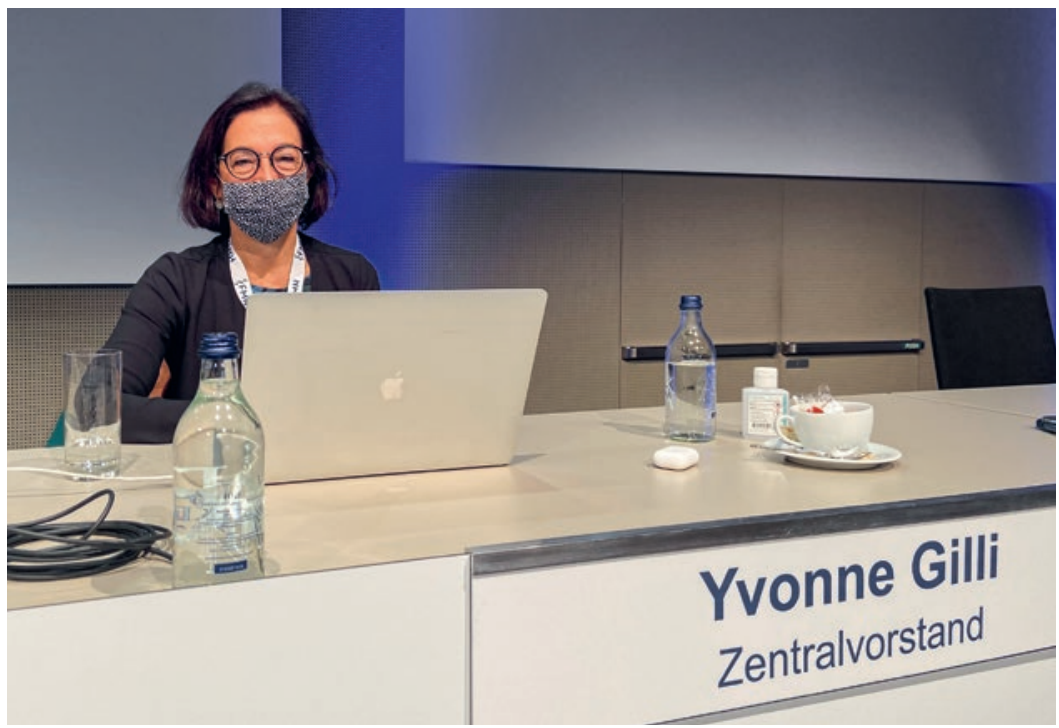

Die neugewählte FMH-Präsidentin, Yvonne Gilli. Sie ist seit vier Jahren Mitglied des Zentralvorstands und verantwortlich für das Departement Digitalisierung/eHealth. Die Delegierten der Ärztekammer wählen mit Yvonne Gilli die erste Frau an die Verbandsspitze.
Das ist eine Aufgabe des Zentralvorstandes und des Präsidiums, hier Brücken zu bauen. Yvonne Gilli / neu gewählte Präsidentin FMH versteht sich als Brückenbauerin. Sie erachtet dieses Amt als eine integrative Aufgabe im Sinne des Sich-im-Innern-Zusammenraufens, um gegen aussen mit gebündelter Kraft aufzutreten. Andere grosse Verbände seien diesbezüglich ein nachahmenswertes Vorbild; so zum Beispiel der Bauernverband, der seit Jahrzehnten so erfolgreich ist, dass er nicht nur riesige Summen an öffentlichen Geldern zugesprochen erhält, sondern auch eine breite Akzeptanz in der Bevölkerung geniesst, und - last but not least - praktisch immer mindestens einen Bundesrat stellt.

Yvonne Gilli / neu gewählte Präsidentin FMH gibt auch der Freude Ausdruck, dass heute eine Vertreterin der jungen Generation in den Zentralvorstand gewählt wurde. Sie betont, dass nicht für die jungen Ärztinnen Lösungen entwickelt werden müssen, sondern mit ihnen.

Zum Schluss bedankt sich Yvonne Gilli / neu gewählte Präsidentin FMH nochmals herzlich bei den Delegierten für das ihr entgegengebrachte Vertrauen, welches ihr Verpflichtung ist, ihnen mit voller Kraft zu dienen. Die Delegierten würdigen ihre Worte mit Applaus.

\subsection{Wahl zweier Vizepräsidentinnen/ Vizepräsidenten FMH}

Zur Wahl stellen sich die beiden bisherigen Vizepräsidenten

- BOSSHARD Christoph

- MATTER Michel Alexandre

Wahlresultat 1. Wahlgang

Gültige Stimmzettel 158; absolutes Mehr 80

Es haben Stimmen erhalten

- BOSSHARD Christoph

- MATTER Michel Alexandre

- SIROKA Jana

- STOFFEL Urs

- QUINTO Carlos

Christoph Bosshard und Michel Matter sind als Vizepräsidenten FMH gewählt. politik. Sie sieht ihre Aufgabe darin, vorausschauend mediale Präsenz und politische Glaubwürdigkeit zu sichern. Um wirksam zu sein, müsse man die politischen Ränkespiele kennen, wie sie Jürg Schlup / Präsident FMH mit dem Schachbrett zu Beginn dieser Sitzung bereits aufgezeigt hat. Man müsse wissen, welcher nächste Schachzug geplant wird, und gleichzeitig dürfe man nicht vergessen, dass in der Schweiz Ziele nur mit Allianzen zu erreichen sind. Und Allianzen sind auch Kompromisse. Allianzen schmieden heisst auch, Hintergrundarbeit zu leisten, ohne dass diese für die ÄK-Delegierten immer offensichtlich ist.

\subsection{Wahl Delegierte Delegiertenversammlung}

Die antragsstellenden Organisationen FMCH, FMPP, KHM, mws, OMCT, SFSM, SMSR, VEDAG, VLSS und VSAO nominierten bis spätestens 5 Wochen vor der ÄKSitzung folgende Delegierte der Delegiertenversammlung der FMH für die Legislatur 2020-2024.

Als Erstes wird über folgende Kandidaturen ohne Altersüberschreitung während der Legislatur (gemäss Art. 22 der FMH-Statuten) abgestimmt:

\section{FMCH}

- EGGER Bernhard (bisher) 
- EGGIMANN Thomas (bisher)

- GENONI Michele

- STAUB Daniel (bisher)

FMPP

- DI GALLO Alain (bisher)

KHM

- AUJESKY Drahomir (bisher)

- CAPAUL Regula (bisher)

- JUNDT-HERMANN Nicole (bisher)

- LUCHSINGER Philippe (bisher)

- ZINGGELER FUHRER Heidi (bisher)

mws

- FLORIO Ivrea

OMCT

- DENTI Franco Eugenio (bisher)

SFSM

- CATHOMAS Gieri (bisher)

- CHRIST Emanuel (bisher)

- LYRER-GAUGLER Philippe A. (bisher)

- SCHWARZKOPF Ann-Kathrin (bisher)

SMSR

- EGGIMANN Philippe (bisher)

- GUSMINI Mauro Walter (bisher)

- MICHEL Jean-Marie

VEDAG

- HASSE Urs

- HILFIKER Esther (bisher)

- KRAMIS Aldo (bisher)

- VOGEL-KÜRSTEINER Hans-Anton (bisher)

VLSS

- LÖVBLAD Karl-Olof (bisher)

VSAO

- BARRILE Angelo

- GRÄDEL-SUTER Marius (bisher)

- RAHM Philipp

- VERDON Aurore

- vakant

Beschluss:

Die DV-Delegierten ohne Altersbeschränkung werden mit 151 Ja, 7 Nein und 3 Enthaltungen bestätigt.

Als Nächstes wird über folgende Kandidaturen mit Altersüberschreitung während der Legislatur (gemäss Art. 22 der FMH-Statuten) abgestimmt:

\section{FMCH}

- MATTARELLI Gianfranco (bisher)

SFSM

- WEBER Marcel (bisher)

VEDAG

- WIDLER-WELTI Josef (bisher)

FMPP

- VALLON Pierre (bisher)
Beschluss:

Die DV-Delegierten mit Altersüberschreitung werden mit 125 Ja, 21 Nein und 12 Enthaltungen bestätigt.

\subsection{Wahl Ersatzdelegierte Delegierten- versammlung}

Die antragsstellenden Organisationen FMCH, FMPP, KHM, mws, OMCT, SFSM, SMSR, VEDAG, VLSS und VSAO nominierten bis spätestens 5 Wochen vor der ÄKSitzung folgende Ersatzdelegierte der Delegiertenversammlung der FMH für die Legislatur 2020-2024.

FMCH

- SCHMID Ralph Alexander (bisher)

FMPP

- ROTA Fulvia

KHM

- KNOBLAUCH Christoph

mws

vakant

OMCT

- CARANZANO Fiorenzo (bisher)

SFSM

- EHMANN Tobias (bisher)

- GREUTER Stefan (bisher)

SMSR

- ARNOLD Pierre (bisher)

vakant

VEDAG

- STEINACHER Alex

- WICKI-FREY Gabriela

VLSS

- PETRE Michaela (bisher)

VSAO

- POROWSKA Aleksandra

- PRINTZEN Gert (bisher)

Beschluss:

Die DV-Ersatzdelegierten werden mit 153 Ja, 1 Nein und 4 Enthaltungen bestätigt.

\subsection{Wahl Präsidentin/Präsident Standes- kommission ${ }^{3}$}

Der ÄK wird vorgeschlagen, bei der Wahl die sprachregionale Verteilung der Fälle gemäss Reglement für die Standeskommission und die Muttersprache der Kandidierenden zu berücksichtigen.

Zur Wahl stellen sich folgende Kandidierende

- MAINIERI Francesca, 1957 (bisher)

- PÖSCHMANN Enrico, 1973

Wahlresultat 1. Wahlgang

Gültige Stimmzettel 160; absolutes Mehr 81

Es haben Stimmen erhalten

- MAINIERI Francesca

- PÖSCHMANN Enrico 
Francesca Mainieri ist als Präsidentin der Standeskommission gewählt.

\subsection{Wahl vier Vizepräsidentinnen/} Vizepräsidenten Standeskommission ${ }^{4}$

Mit der Wahl entscheidet die ÄK auch darüber, die Altersgrenze für jene Kandidierenden hinauszuschieben, die während der Legislatur die Altersgrenze (gemäss Art. 22 der FMH-Statuten) erreichen oder überschreiten.*

Zur Wahl stellen sich folgende Kandidierenden (alphabetische Reihenfolge)

- FAVROD-COUNE Charles Abram (bisher)*

- MANSER Beat (bisher)

- PÖSCHMANN Enrico

- REYMOND Jean-Marc (bisher)

- SARRAJ Ali

- WENGER Mathias (bisher)

Wahlresultat 1. Wahlgang

Gültige Stimmzettel 138; absolutes Mehr 70

Gewählt als Vizepräsidenten der Standeskommission sind

- REYMOND Jean-Marc

- MANSER Beat

- WENGER Mathias

- FAVROD-COUNE Charles Abram

Zusätzlich Stimmen erhalten haben

- SARRAJ Ali

- PÖSCHMANN Enrico

\subsection{Wahl Mitglieder Geschäftsprüfungs-} kommission FMH $^{5}$

Mit der Wahl entscheidet die ÄK auch darüber, die Altersgrenze für jene Kandidierenden hinauszuschieben, die während der Legislatur die Altersgrenze (gemäss Art. 22 der FMH-Statuten) erreichen oder überschreiten.*

Zur Wahl stellen sich folgende Kandidierenden (alphabetische Reihenfolge)

- BACHMANN HEINZER Rosilla

- GHISLETTA Nicola Edoardo

- LAREIDA Jürg Michael (bisher)

- PÖSCHMANN Enrico

- VUILLEMIN Philippe (bisher)*

- ZWAHLEN Daniel Rudolf

Wahlresultat 1. Wahlgang

Gültige Stimmzettel 133; absolutes Mehr 67

Gewählt als Mitglieder der Geschäftsprüfungskommission sind

- BACHMANN HEINZER Rosilla

4 Die Wahl findet am Folgetag statt.

5 Die Wahl findet am

Folgetag statt.
- LAREIDA Jürg Michael

121

- ZWAHLEN Daniel Rudolf

- VUILLEMIN Philippe
- GHISLETTA Nicola Edoardo

Zusätzlich Stimmen erhalten haben

- PÖSCHMANN Enrico

22

- LYRER Philippe

\section{Budgetstabilisierungsmassnahmen}

3.1. Abschluss Budgetstabilisierungsmassnahmen Patrick Egger / Leiter Abteilung Finanzen und Verwaltung, Stv. Generalsekretär zeigt anhand des Umsetzungsplans 2019 den Schlussstand der Arbeiten zu den Budgetstabilisierungsmassnahmen auf.

In einer Gesamtbetrachtung zeigt er die Gesamteinsparungen der letzten vier Jahre (2016-2019). Von den geplanten CHF 5,8 Mio. konnten Einsparungen von CHF 5,4 Mio. realisiert werden. Dies entspricht 93\% der Massnahmen. Folgende Beträge wurden in den vergangenen vier Jahren eingespart: 2016: CHF 3,5 Mio., 2017: CHF 1,4 Mio., 2018: CHF 0,2 Mio. und 2019: CHF 0,3 Mio. Die ÄK nimmt den Abschlussbericht zu den Budgetstabilisierungsmassnahmen der Jahre 2016 bis 2019 zur Kenntnis.

\section{Jahresberichte 2019}

\subsection{Jahresbericht 2019 des SIWF}

Werner Bauer / Präsident SIWF erläutert folgende Punkte des Jahresberichtes SIWF 2019:

- EPAs (Entrustable Professional Activities = anvertraubare, professionelle Aktivitäten).

Eine EPA ist eine in sich abgeschlossene, für das jeweilige Arbeitsgebiet typische klinische Tätigkeit, die alle dafür relevanten Kenntnisse, Fertigkeiten und Haltungen zusammenführt: Ein KompetenzSet, das die vielen Positionen des Lernziel-Katalogs sowie zum Teil auch Prüfungen ersetzen soll.

- Projektförderung: Das SIWF lädt im November wiederum zum Einreichen von Projekten ein, mit denen die Weiterbildung unterstützt, erleichtert und verbessert werden kann.

- Royal College of Physicians / «Swiss RCP»: Seit 2012 führt das SIWF zusammen mit dem Royal College of Physicians zweimal jährlich unverändert populäre "teach the teachers»-Workshops zu Themen wie "Teaching in clinical settings», «How to support an underperforming trainee», «Effective strategies for feedback and assessment» oder «Basic leadership skills» durch.

- Visitationen (>150/J.)

Neben der Umfrage bei allen Ärztinnen und Ärzten in Weiterbildung (ETH/SIWF) sind die Visitationen das wirksamste Instrument zur Unterstützung, Sicherung und Kontrolle der Weiterbildung (Visi- 
tationsleiter/-in aus dem betreffenden Fachgebiet und fachfremde Expertin/fachfremder Experte sowie VSAO-Vertreterin/Vertreter).

- Strukturveränderungen an den Weiterbildungsstätten

Strukturelle Veränderungen (Teilzeitarbeit, Verschiebung von Eingriffen von stationär zu ambulant, Fusionen, Verbünde/Netzwerke, «multi-site»Weiterbildungsstätten, interdisziplinäre Zentren/ Bereiche usw.) stellen zunehmende Herausforderungen an das SIWF und die Fachgesellschaften in Form von Anpassung der Weiterbildungsordnung und entsprechend auch der Weiterbildungsprogramme, -konzepte und -verträge.

- Fortbildung

(im Fokus der Plattform «Zukunft ärztliche Bildung» BAG/GDK). Die Fortbildung muss in der Verantwortung des SIWF und der Fachgesellschaften bleiben, und dies ohne zusätzliche Regulierungen.

Mit Osler-Zitaten verabschiedet sich Werner Bauer / Präsident SIWF als scheidender Präsident des SIWF und bedankt sich für das ihm immer entgegengebrachte Vertrauen.

Christoph Hänggeli / Geschäftsführer SIWF ergänzt den Jahresbericht SIWF 2019 mit folgenden Punkten:

\section{Weiterbildung}

Inzwischen gibt es 134 Fachgebiete und überall sind Prüfungen, Kurse und Kongresse angesagt, die aufgrund der Covid-Situation ausfallen oder verschoben werden müssen. Das ist eine sehr grosse Herausforderung für die Fachgesellschaften und das SIWF. Es müssen Sonderregelungen erlassen werden, damit die Facharzttitel weiterhin in geordnetem Rahmen rechtlich einwandfrei erteilt werden können.

\section{Fortbildung}

Für das Jahr 2020 hat das SIWF eine "Covid-Gutschrift» von 25 Credits im Fortbildungsprotokoll eingetragen; je nach Verlauf der 2. Welle kann eine weitere Gutschrift gesprochen werden.

Rückstand bei der Dossierbearbeitung

Aufgrund der Covid-Probleme ist es bei den DossierBearbeitungen zu grossen zeitlichen Verzögerungen gekommen. Mit einem Massnahmenplan ist die Geschäftsstelle des SIWF bestrebt, die Dienstleistungen so rasch als möglich wieder in der gewohnten Qualität anzubieten.

e-Logbuch

Das Projekt e-Logbuch ist in Bezug auf die Entwicklung der Software abgeschlossen, kann aber wegen der anderweitig verwendeten Ressourcen im Moment nicht umgesetzt werden.

Revision MedBG

Das vollständige Ärzteregister ist per 1.1.2020 definitiv in Kraft getreten. Ohne geprüftes Arztdiplom und Eintrag im Register darf niemand den Arztberuf in der Schweiz ausüben.

\section{WBO}

Das SIWF hat im Bereich der privatrechtlichen Titel folgende Umwandlungen/Neuschaffungen beschlossen:

- Umwandlung in interdisziplinäre Schwerpunkte

- Neuropathologie (SSNPath)

- Klinische Notfallmedizin (SGNOR)

- Psychosomatische und Psychosoziale Medizin (SAPPM)

- Neue interdisziplinäre Schwerpunkte

- Wirbelsäulenchirurgie (SGNC und SO)

- Ernährungsmedizin (GESKES)

- Neue Schwerpunkte

- Gynäkologische Senologie

- Chirurgische Senologie

\section{Teilzeit}

Neu sind unter bestimmten Umständen auch Weiterbildungsperioden im Pensum von 20 bis $50 \%$ anrechenbar. Alle detaillierten Informationen zum Jahresbericht sind elektronisch unter www.siwf.ch abrufbar.

\section{Antrag:}

Die Geschäftsleitung des SIWF beantragt der ÄK, den Jahresbericht 2019 des SIWF zu genehmigen.

\section{Beschluss:}

Der Antrag wird mit 161 Ja, 1 Nein und 5 Enthaltungen angenommen.

\subsection{Jahresbericht 2019 der FMH}

Ursina Pally Hofmann / Generalsekretärin FMH und Leiterin Rechtsdienst zeigt den Jahresbericht FMH 2019, der am 8. April 2020 publiziert wurde und auf der Homepage unter www.fmh.ch zu finden ist.

Der Inhalt umfasst folgende Punkte:

- Personelles

- Meilensteine

- Politik

- Ärzteschaft

- Tätigkeiten

- Jahresrechnung

Im Lagebericht sind folgende Themen zu finden:

- Gesundheitspolitische Lage

- Mitarbeitende

- Durchführung Risikobeurteilung

- Mitglieder

- Entwicklungstätigkeit

- Aussergewöhnliche Ereignisse

- Aussichten

Ursina Pally Hofmann / Generalsekretärin FMH und Leiterin Rechtsdienst regt an, den Jahresbericht im Detail nachzulesen. 


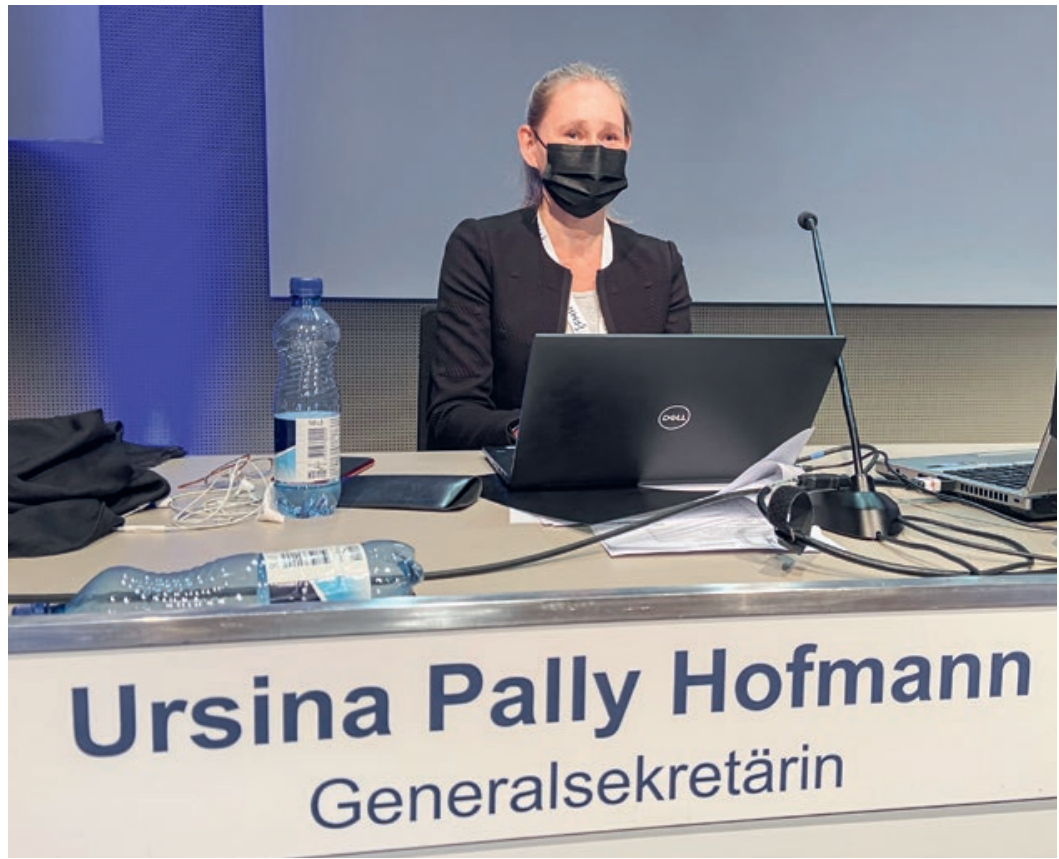

Ursina Pally Hofmann, Generalsekretärin der FMH und Abteilungsleiterin Rechtsdienst.

\author{
Antrag: \\ Der ZV FMH beantragt der ÄK, den Jahresbericht 2019 \\ der FMH zu genehmigen. \\ Beschluss: \\ Der Antrag wird mit 154 Ja, 1 Nein und 3 Enthaltungen \\ angenommen.
}

\section{Jahresrechnung 2019}

\subsection{Erfolgsrechnung 2019 des SIWF}

Christoph Hänggeli / Geschäftsführer SIWF informiert über die Rechnung 2019, die einen Gewinn von CHF 74000 ausweist (bei einem budgetierten Gewinn von CHF 2000). Damit hat das SIWF die roten Zahlen der Vorjahre verlassen; 2018 wurde noch ein Verlust von CHF 379000 ausgewiesen. Der Abwärtstrend ist gestoppt und die Finanzsituation des SIWF ist konsolidiert.

Im Vergleich zum Budget sind folgende Abweichungen erwähnenswert:

Ertragsseite: Weniger Ertrag bei den Facharzttiteln und Schwerpunkten; dafür Mehrertrag im gleichen Umfang bei der Zertifizierung der Weiterbildungsstätten und im Bereich Fortbildung.

Aufwandseite: Weniger Aufwand beim Personal, beim e-Logbuch und bei der Akkreditierung steht etwa gleichem Mehraufwand bei den Visitationen, der Rechtsberatung und den Rückstellungen gegenüber.

Der Vermögensstand per 1.1.2020 beträgt $\mathrm{CHF}$ 2486000.

\subsection{Erfolgsrechnung 2019 der FMH}

Patrick Egger / Leiter Abteilung Finanzen und Verwaltung, Stv. Generalsekretär erläutert die Erfolgsrechnung 2019 der FMH, welche mit einem Gewinn von CHF 1919200.94 abschliesst. Die Mitgliederbeiträge (inklusive Sonderbeiträge) haben insbesondere aufgrund des Wegfalls des Sonderbeitrages für die EMH im Vergleich zum Jahr 2018 abgenommen. Die ordentlichen Mitgliederbeiträge haben im Vergleich zum Vorjahr ebenfalls einen leichten Rückgang zu verzeichnen.

Die Aufwands- und Ertragsentwicklung hat sich im Vergleich zu den Vorjahren unter anderem aufgrund des Sanierungsprojektes der Elfenstrasse erhöht.

\subsection{Konsolidierte Jahresrechnung 2019}

Patrick Egger / Leiter Abteilung Finanzen und Verwaltung, Stv. Generalsekretär erläutert die konsolidierte Jahresrechnung, welche sich aus den zwei Jahresrechnungen 2019 von FMH und SIWF zusammensetzt. Die Bilanz zeigt ein Umlaufvermögen von CHF 25,806 Mio. und ein Anlagevermögen von CHF 6,829 Mio. Das Fremdkapital beträgt CHF 16,956 Mio., das Eigenkapital CHF 15,678 Mio. Die Bilanzsumme beträgt CHF 32,635 Mio. Die Erfolgsrechnung weist einen Gewinn von CHF 1,993 Mio. für die FMH und das SIWF aus.

\subsection{Konzernrechnung 2019 der FMH}

Patrick Egger / Leiter Abteilung Finanzen und Verwaltung, Stv. Generalsekretär berichtet, dass folgende Beteiligungen konsolidiert wurden:

Health Info Net AG mit einer Beteiligung von 57,67\% und einem Kapital von CHF 3 Mio. wird vollkonsolidiert. EMH AG mit einer Beteiligung von 55\% und einem Kapital von CHF 1,5 Mio. wird vollkonsolidiert. Die ats-tms AG mit einer Beteiligung von 50\% und einem Kapital von CHF 0,1 Mio. wird quotenkonsolidiert. Die AD Swiss Net AG mit einer Beteiligung von 10\% und einem Kapital von CHF 0,4 Mio. wird mit der EquitiyMethode konsolidiert.

Die Bilanz zeigt ein Umlaufvermögen von CHF 36,381 Mio. und ein Anlagevermögen von CHF 7,377 Mio. Das Fremdkapital beträgt CHF 23,177 Mio., das Eigenkapital CHF 20,581 Mio. Die Bilanzsumme weist CHF 43,758 Mio. auf. Die Erfolgsrechnung weist einen Ertrag von CHF 52,561 Mio. und einen Aufwand von CHF 50,068 Mio. auf. Das Jahresergebnis 2019 der Konzernrechnung zeigt einen Gewinn von CHF 2,493 Mio.

\subsection{Bericht der Revisionsstelle}

Jürg Schlup / Präsident FMH begrüsst Fabian Mollet / Revisionsstelle $B D O$ und übergibt ihm das Wort. Fabian Mollet / Revisionsstelle BDO bestätigt die Prüfung der Jahresrechnung 2019 (FMH inkl. SIWF) durch die Revi- 
sionsstelle. Die Kontrollstelle hat die Revision der Jahres- und Konzernrechnung ohne Schwierigkeiten durchgeführt. Fabian Mollet / Revisionsstelle BDO bestätigt, dass die Rechnungen dem Gesetz und den Statuten entsprechen, dass ein entsprechendes IKS Internes Kontrollsystem - zur Erstellung dieser Jahresrechnung existiert. Die Revisionsstelle empfiehlt, die Jahresrechnung 2019 wie auch die Konzernrechnung 2019 zu genehmigen.

\subsection{Bericht der GPK}

Adrian Sury / Präsident GPK bedankt sich beim FMHTeam für die grossartige Leistung, die ÄK innerhalb kürzester Zeit elektronisch auf die Beine zu stellen, und berichtet anschliessend über die Themen der Sitzungstätigkeit 2019-2020 mit folgenden Hauptthemen:

- Finanzfragen (Abschluss, Budget und Vermögenslage)

- Erfolgsrechnung 2019

- Budget 2021

- Abschluss Budgetstabilisierung

- ÄK Oktober 2014: Antrag der GPK zur Schaffung von operativem finanziellem Spielraum

- ÄK Oktober 2015 heisst die Vorschläge des ZV gut

- ÄK Oktober 2020: 92,99\% der Massnahmen sind umgesetzt (FMH und SIWF)

- Dies entspricht CHF 5,384 Mio.

- Risikobeurteilung (System und Prozesse) Der ZV erstellt jährlich im Herbst eine neue Risikobeurteilung.

- Internes Kontrollsystem IKS

- IKS Debitoren und Fakturierung $\rightarrow$ hohes Kontrollbewusstsein, IKS-Dokumentation wird 2020 finalisiert

- IKS Abschlusserstellungsprozess $\rightarrow$ sehr gut

- In Entwicklung sind Unterschriftsreglement und IKS Debitoren

- Datenschutzkonzept

- Revidiertes Datenschutzgesetz Schweiz wird voraussichtlich 2021 eingeführt.

- In der FMH sind die Vorschriften zu 58\% umgesetzt; im SIWF zu 36\%.

- Die GPK regt an, dass die Umsetzung im 2021 abgeschlossen wird.

- GEVER (Dokumentationsarchiv für die Geschäftsverwaltung)

- Einführung ab August 2020; Migration aus dem bestehenden System erfolgreich

- e-Logbuch 2.0

- Es ist weitgehend umgesetzt, und dies ohne Kostenüberschreitungen.

- Gesamtsanierung Elfenstrasse (Stand: Ende August 2020)

- ÄK-Beschluss vom 9.5.2019: CHF 10980000 ( $\pm 10 \%)$
- Prognose basierend auf Vergabeverträgen: CHF 9665965

- Bisher getätigte Zahlungen: CHF 1388979

- Der Zusatz-Aufwand im Bereich der Schadstoff- sowie der Abwasser-Sanierung ist damit problemlos aufgefangen.

- Fakturierung Zentralbeiträge/Datensynchronisation

- Die Datendrehscheibe für das Ersatzprojekt «Datensynchronisation mit Basisorganisationen und Fakturierung Zentralbeiträge» wurde installiert und initialisiert.

- Die veraltete Datenstruktur wurde durch die ICT bereinigt.

- Pilotprojekte mit der AGZ (Navision) und dem Aargauischen Ärzteverband (EPOS) sind angelaufen.

- Zweckmässigkeit der FMH-Strukturen - Organigramm

- 2019 wurde ein neues Organigramm eingeführt, das die Zuständigkeiten GS - ZV - SIWF besser regeln soll.

- Abschluss einer Zusammenarbeitsvereinbarung zwischen der Generalsekretärin FMH und dem Geschäftsführer SIWF

- FMH und SIWF treten faktisch (nicht rechtlich) als zwei eigenständige Institutionen auf.

- Nutzung gemeinsamer Ressourcen und Schnittstellen

- Gemeinsame Projekte nach Bedarf

- Departemente FMH

- Zuständiges Mitglied ZV ist Departementsverantwortlicher.

- Resultat: klare Verantwortungen

- Zweckmässigkeit der FMH-Strukturen - Delegiertenversammlung (DV)

- DV: Ausschuss der ÄK oder Senat? Kompetenzen?

- Anlässlich einer Sitzung mit dem DV-Präsidenten

Dr. Pierre Vallon am 15.11.2019 konnten die Zweifel der GPK weitgehend ausgeräumt werden:

- Die DV im Gesamtsystem der FMH funktioniert gut, wenn die Aufgabenteilung Legislative zu Exekutive sauber stattfindet.

- Für Pierre Vallon hat sich die DV in ihrer aktuellen Zusammensetzung bewährt.

- Erfolgsrechnung und Bilanz

-FMH: Leicht tiefere Mitgliederbeiträge trotz Mitgliederzuwachs (+1171 auf 42703 Ärztinnen und Ärzte) und tieferer Gesamtaufwand (nicht ausgeführte Projekte)

- SIWF: Höherer Dienstleistungsertrag (neue/höhere Tarife für Leistungen); kostenintensive ITProjekte finanziell gut im Griff 
- Erneute Bildung einer Reserve für den Umbau Ärztehaus Elfenstrasse

- Weniger Abschreibungen als geplant (Ärztehaus)

- Der Personalaufwand hat gegenüber 2018 abgenommen, obgleich das Personal um 7 VZÄ (Vollzeitäquivalente) erhöht wurde.

- Die Rückstellungen per Ende 2019 entsprechen Bedürfnissen der FMH. Die Risiken der steuerlichen Anerkennung wurden so weit als möglich reduziert.

- Problem Steuerverwaltung: Seit Jahren keine definitive Veranlagung mehr erhalten. Das GS setzt Druck auf.

-IT-Kosten, inkl. e-Logbuch 2.0 durch ausgezeichnete Projektleitung im Griff

- Revision der SIWF-Tarife (Visitationen, Zertifizierungen etc.) hat sofort Auswirkungen gezeigt.

- Akkreditierung durch BAG personell und finanziell extrem aufwendig; Rückstellungen wurden vorgenommen.

- Erfolgsrechnung und Bilanz - Geschäftsführung

- Liquidität stets ausgezeichnet

- Rendite der Anlagen in Wertschriften im Positivbereich per 31.12.2019

- Beschlussantrag der GPK:

Die GPK empfiehlt die Annahme der Jahresrechnung zuhanden der ÄK im Herbst:

1. Genehmigung Erfolgsrechnung 2019 des SIWF

2. Genehmigung Erfolgsrechnung 2019 der FMH

3. Genehmigung der konsolidierten Jahresrechnung 2019 der FMH

4. Genehmigung der Konzernrechnung 2019 der FMH

- Meilensteine der GPK 2008 bis 2020:

- Sensibilisierung für klare Strukturen und Verhältnisse zwischen Organen und Gremien (strategisch-operativ, ZV-GS, FMH-SIWF, DV-ÄK, Aufgaben der GPK)

- Klare Verträge mit den Beteiligungsgesellschaften (vor allem EMH, aber auch HIN) und FMH Services (Lizenzgebühren)

- Budgetstabilisierung

Adrian Sury / Präsident GPK dankt als scheidender Präsident der GPK den Präsidenten der FMH und des SIWF, dem ZV, dem Generalsekretariat sowie der Geschäftsstelle SIWF für die angenehme Zusammenarbeit.

Genehmigung der Jahresrechnung 2019

Antrag:

Der ZV der FMH beziehungsweise die Geschäftsleitung des SIWF beantragt der ÄK, die Jahresrechnung 2019 zu genehmigen. Im Detail genehmigt sie folgende Rechnungen:
1. Die Erfolgsrechnung 2019 des SIWF

2. Die Erfolgsrechnung 2019 der FMH

3. Die konsolidierte Jahresrechnung 2019 der FMH

4. Die Konzernrechnung 2019 der FMH

Ordnungsantrag Präsident FMH:

Der ÄK wird beantragt, die Jahresrechnung 2019 in einer Gesamtabstimmung (Ziffer 5.1 bis 5.4 ) zu erledigen.

Beschluss:

Die ÄK beschliesst, die Jahresrechnung 2019 mit 168 Ja, 3 Nein und 0 Enthaltung als Gesamtabstimmung (Ziffer 5.1 bis 5.4) zu erledigen.

Beschluss:

Die Jahresrechnung 2019 der FMH (Ziffer 5.1 bis 5.4) wird mit $118 \mathrm{Ja}, 3$ Nein und 8 Enthaltungen angenommen.

\section{Dechargen-Erteilung}

6.1. Dechargen-Erteilung Geschäftsleitung SIWF Antrag Geschäftsleitung SIWF:

Die ÄK beschliesst, den Empfehlungen der Kontrollstelle sowie der Geschäftsprüfungskommission (GPK) zu folgen und der Geschäftsleitung SIWF für das Geschäftsjahr 2019 Decharge zu erteilen. Beschluss:

Der Antrag wird mit $163 \mathrm{Ja}, 1$ Nein und 2 Enthaltungen angenommen.

\subsection{Dechargen-Erteilung Zentralvorstand FMH} Antrag ZV:

Die ÄK beschliesst, den Empfehlungen der Kontrollstelle sowie der Geschäftsprüfungskommission (GPK) zu folgen und dem Zentralvorstand FMH für das Geschäftsjahr 2019 Decharge zu erteilen. Beschluss:

Der Antrag wird mit 161 Ja, 0 Nein und 3 Enthaltungen angenommen.

\section{Wahl der Revisionsstelle (BDO AG) für die Periode 2021-2022}

Der ÄK wird die erneute Wahl der BDO AG aus folgenden Gründen empfohlen:

Patrick Egger / Leiter Abteilung Finanzen und Verwaltung, Stv. Generalsekretär bestätigt die Zusammenarbeit mit der BDO als überaus positiv. Die Abteilung Finanzen und Verwaltung ist seit zwei Jahren in einer neuen Zusammensetzung aktiv. Die Konzernrechnung wurde nun das zweite Mal erstellt. Das Interne Kontrollsystem (IKS) wird weiter optimiert. Die Kontinuität all dieser Arbeiten mit gleichbleibender Kontroll- 


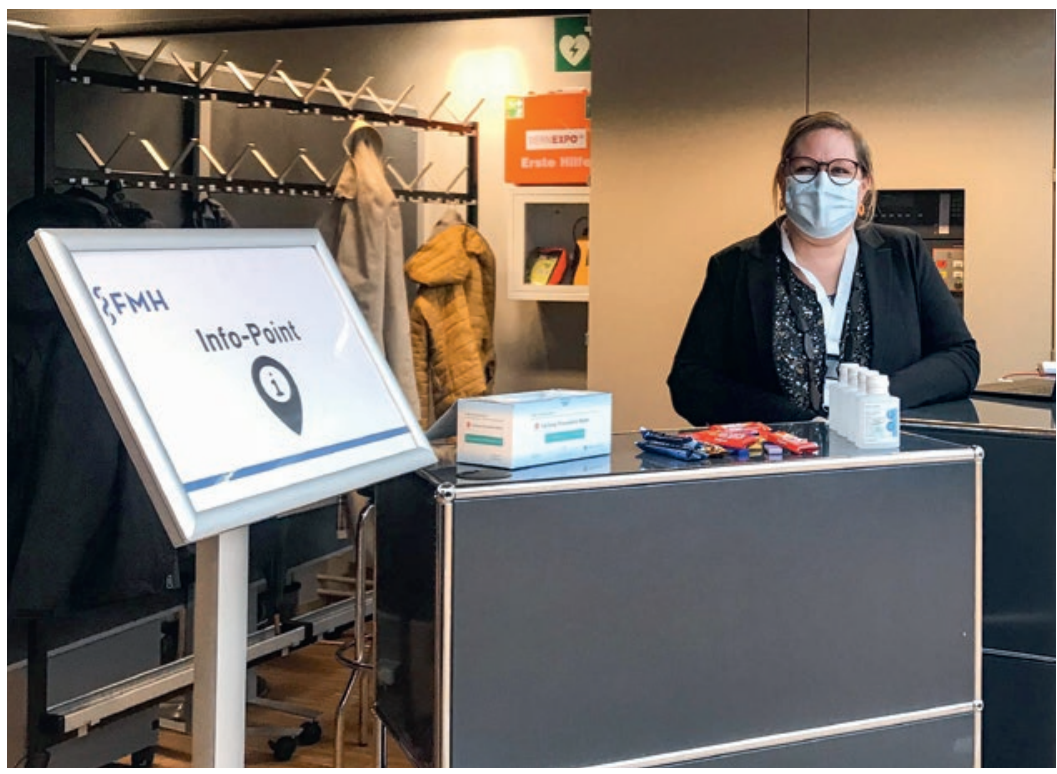

Claudia Marthaler am Info-Point steht für alle Fragen Red und Antwort.

stelle ist wichtig und sinnvoll. Gesetzlich ist es nicht vorgeschrieben, die Revisionsstelle zu wechseln. Vorgeschrieben ist aber nach Art. 730, Abs. 2 OR, dass der leitende Revisor längstens während sieben Jahren die ordentliche Revision durchführen kann. Beim Mandat der BDO AG für die Revision der FMH wurde der Wechsel der Revisionsleiter von Herrn Simon Kehrli zu Herrn Fabian Mollet nach sechs Jahren vollzogen.

Antrag:

Die ÄK wählt die Revisionsgesellschaft BDO in Bern als Kontrollstelle für weitere zwei Jahre (Jahresrechnungen 2020 und 2021).

Beschluss:

Der Antrag wird mit $167 \mathrm{Ja}, 2$ Nein und 2 Enthaltungen angenommen.

\section{Grundsätze neue Finanzierung der ärzteeigenen Datensammlung: 1. Lesung}

Jürg Schlup / Präsident FMH begrüsst Philip Molin, Geschäftsführer NewIndex AG und übergibt ihm und Urs Stoffel / ZV-Mitglied und Departementsverantwortlicher Ambulante Versorgung \& Tarife das Wort. Urs Stoffel / ZV-Mitglied und Departementsverantwortlicher Ambulante Versorgung \& Tarife hält einleitend fest, dass es sich bei diesem Vorschlag für die Neuorganisation der Datensammlung heute vorerst um ein Informationstraktandum handelt.

Philip Molin, Geschäftsführer NewIndex AG erläutert, weshalb eine solide, ärzteeigene Datengrundlage für eine ärztliche Standesorganisation unabdingbar ist. Es geht darum, in der jetzigen, schwierigen Phase der Um- setzung der Tarifrevision TARDOC, die vielfältigen Herausforderungen erfüllen zu können. Gleichzeitig stehen die Kantone bei den Verhandlungen oder Festsetzungen ihrer Taxpunktwerte unter massivem Druck. Sie sind vital auf eine ärzteeigene Datengrundlage für die Verhandlungen und Stellungnahmen bei Festsetzungen angewiesen.

Für die Ärzteschaft bestehen mehrere gesetzlich verankerte Datenlieferpflichten gegenüber dem Bund. Diese Daten sind dem Bund kostenlos zur Verfügung zu stellen. Eine qualitativ hochwertige ärzteeigene Datensammlung ist deshalb neben der gesetzlichen Pflicht auch bezüglich der Datenparität mit dem Bund alternativlos. Das Aufrechterhalten einer entsprechenden Infrastruktur auf nationaler Ebene durch die NewIndex ist für diese Aufgaben absolut zwingend.

Die Veränderung der politischen, rechtlichen und organisatorischen Rahmenbedingungen der Datensammlung in den letzten 15 Jahren macht Anpassungen in der Datensammlung und auch ihrer historisch gewachsenen Finanzierung notwendig. Aufgrund der komplexen Vertragssituation und Finanzierung der Datensammlung ist es zunehmend schwierig, auf den raschen Wandel im ambulanten Bereich zu reagieren.

Von den Daten profitieren alle ambulant tätigen Ärzte und Verbände. Die Vorhalteleistungen - Sammeln, Veredeln und Halten der Daten - verursachen dabei einen Grossteil der Kosten. Die Finanzierung war zu Beginn sinnvoll organisiert, aber zunehmend fehlt es an Übereinstimmung mit der Nutzung der Datensammlung: finanziert wird die ärzteeigene Datensammlung heute fast ausschliesslich durch die einzelnen Teilnehmer (TC-Kunden) der Datensammlung und durch den "NAKO Sonderbeitrag», während grosse Leistungsbezüger wie KGs und FGs keinen adäquaten Anteil an die kostenintensiven Vorhalteleistungen bezahlen. Auch die Ärzte, welche sich an der Finanzierung nicht beteiligen, profitieren von der datenbasierten Interessenvertretung durch die Standesorganisationen («Trittbrettfahrer»). Die Daten der Innerschweiz und des Kanton Waadt fehlen zudem heute in der ärzteeigenen Datensammlung.

Für die Zukunft braucht es eine solidarische Finanzierung der gesamten Ärzteschaft zur Sicherstellung einer flächendeckenden Datensammlung, Datenhaltung und Datenverwertung.

Der Vorschlag zur neuen Finanzierung stützt sich auf die folgenden drei Grundsätze ab:

- Auf der lokalen/regionalen Ebene werden die Datenlieferanten, d.h. die einzelnen Praxen, wie bisher primär und bevorzugt durch ihre TrustCenter betreut; neu wird die Finanzierung der TrustCenterDienstleistungen zwischen den Kantonalen Ärzte- 
gesellschaften und den Trust-Centern bilateral verhandelt.

- Auf der nationalen Ebene wird die heutige Datensammlung ("Sammlung») und die darauf aufbauenden Grundleistungen («Verwertung») als ärzteeigenes Datencenter betrieben. Das ärzteeigene Datencenter mit allen für die Sammlung und Verwertung notwendigen technischen Aspekten wird solidarisch durch die FMH finanziert, um die nationale Datennutzung für alle standespolitischen Themen sicherzustellen.

- Alle anderen Leistungen sind vom einzelnen Leistungsbezüger individuell zu bestellen und zu bezahlen.

Für den heute teilnehmenden Arzt erfolgt eine Umlagerung vom Einzelbetrag TC auf den Mitgliederbetrag FMH/KG. Nachdem sich in Zukunft alle freipraktizierenden Ärzte an der Finanzierung beteiligen werden, wird es für den einzelnen Arzt, der schon bisher an der Datensammlung mitgemacht hat, günstiger. Für Ärztinnen und Ärzte, welche bisher keinem TC oder der ZDS angeschlossen sind, wird es hingegen teurer.

Die TrustCenter werden durch die solidarische Finanzierung der Vorhalteleistungen einerseits von den entsprechenden bisherigen Aufwänden entlastet, und anderseits sinken die Basiskosten der Arbeitsinstrumente (Praxisspiegel, TX-Analyzer), welche die Grundlage für die Dienstleistungen der TrustCenter wie Praxis-Beratungen, Support bei wzw-Verfahren und Unterstützung der Ärzte bei der Datenerfassung (ROKO, MAS) bilden. Neu werden die TrustCenter eine Lizenzgebühr für den Anschluss an die Datensammlung und die Nutzung der technischen Infrastruktur der TMA entrichten, statt der heutigen rechnungsvolumenabhängigen Gebühren.

Mit dem Vorschlag zur neuen, sachgerechten und verursacherkonformen Finanzierung soll eine Anpassung an die aktuellen Rahmenbedingungen und Bedürfnisse der Ärzteschaft erfolgen. Das Ziel ist die langfristige Sicherung einer schweizweiten, einheitlichen und solidarisch finanzierten, ärzteeigenen Datensammlung.

Langfristige Sicherung der Existenz der Datensammlung durch:

- Solidarische Finanzierung der Vorhalteleistungen durch die gesamte Ärzteschaft

- Eliminierung der «Trittbrettfahrer», finanzielle Gleichbehandlung aller von der Datensammlung profitierenden Ärztinnen und Ärzte und finanzielle Entlastung der heutigen Teilnehmer

- Realisierung der Kongruenz zwischen den Leistungs- und Geldflüssen im ärzteeigenen Datencenter gemäss betriebswirtschaftlichen Kriterien.
Wiedererlangung einer nationalen Abdeckung der Datensammlung durch:

- Öffnung der Datensammlung mit Einbindung aller datenanliefernden Organisationen

- Gleichbehandlung aller datenanliefernden Organisationen und Aufhebung der finanziellen Hürden für deren Anschluss an das ärzteeigene Datencenter

- Transparente und verbindliche Bedingungen für die Datenanlieferung zur Sicherstellung der einheitlichen und hohen Datenqualität.

Vereinfachung des Vertragskonstrukts aus der Gründerzeit durch:

- Anpassung der Verträge an die aktuellen Bedürfnisse der Ärzteschaft und an die Datennutzung

- Verbesserung der Transparenz (Rollen und Verantwortlichkeiten)

- Eliminierung von nicht mehr zeitgemässen und gesetzeswidrigen Vertragskonditionen (TerritorialMonopol).

\section{Datenschutz}

Die Server von NewIndex haben denselben Standard wie bei Banken und stehen in hochsicheren Rechenzentren in der Schweiz.

- Schutz Patientendaten: Anonymisierung der Patientendaten beim Transport ins NewIndex-System

$\rightarrow$ NewIndex arbeitet nur mit Sachdaten, nicht mit Personendaten (gemäss CH DSG).

- Schutz Arztdaten: Anonymisierung der Arztdaten bei der Datenverarbeitung

$\rightarrow$ Ärztegesellschaften erhalten nur Auswertungen, in denen einzelne Ärztinnen und Ärzte nicht identifizierbar sind.

- Schutz Interessen Ärzteschaft: Regeln zur Datennutzung (NAKO-Kodex)

$\rightarrow$ Das NAKO-Gremium überwacht die Datennutzung im Einklang mit den Interessen der Ärztinnen und Ärzte.

Urs Stoffel / ZV-Mitglied und Departementsverantwortlicher Ambulante Versorgung \& Tarife bedankt sich bei Philip Molin, Geschäftsführer NewIndex AG für die Ausführungen.

- Der Vorschlag zur neuen Finanzierung der ärzteeigenen Datensammlung wurde im Verwaltungsrat der NewIndex AG in einer Klausur und in einem Workshop erarbeitet. Aktuell wird der Vorschlag den Akteuren und Partnern (TrustCenter und Kantone) präsentiert und deren Input aufgenommen.

- Der Vorschlag wurde auch den Präsidenten der Kantonalen Ärztegesellschaften an der Präsidentenkonferenz der FMH vom 31.10.2019 sowie in einem Workshop mit den TCs und auch dem Zentralvorstand und der DV-FMH vorgestellt. 
Es geht nun darum, dass man sich an den Gedanken gewöhnt, wie eine faire und verursachergerechte Finanzierung und dadurch auch eine klare Transparenzerhöhung und Vereinfachung des historisch gewachsenen Konstrukts möglich wäre. Bei einer zweiten Lesung in der ÄK wird ein konsolidierter Vorschlag mit entsprechenden Kostenfolgen vorliegen, über welchen dann abgestimmt werden muss.

Antrag:

Die ÄK nimmt Kenntnis von den Grundsätzen für eine neue Finanzierung der ärzteeigenen Datensammlung und stimmt der Weiterverfolgung dieses Konzeptes zu.

Beschluss:

Der Antrag wird mit 133 Ja, 8 Nein und 16 Enthaltungen angenommen.

\section{9. Änderungen in den Statuten}

\subsection{Auswirkungen Vollzug MedReg auf FMH-}

Mitgliedschaft

Claudia Blackburn, Abteilungsleiterin Mitgliedschaften

$D L M$ präsentiert den Antrag auf Statutenänderung, welcher auf einer Änderung des MedBG basiert, die am 1.1.2018 in Kraft getreten ist mit einer Übergangsfrist von zwei Jahren. Diese besagt, dass per 1.1.2020 nur noch Ärzte, die im Medizinalberuferegister der Eidgenossenschaft eingetragen sind, ärztliche Tätigkeiten in der Schweiz ausüben können.

In Anbetracht dieser Rechtslage hat der Zentralvorstand der FMH beschlossen, ab 1. Januar 2018 nur im MedReg eingetragene Ärzte aufzunehmen. Ärzte, die bereits vor dem 1. Januar 2018 FMH-Mitglied waren und nicht im MedReg eingetragen waren, wurden per Schreiben vom 8. August 2019 auf die neue Rechtslage aufmerksam gemacht und gebeten, ihr Arztdiplom möglichst rasch eintragen zu lassen. Im Ärzteregister der FMH (doctorfmh.ch) dürfen per 1.1.2020 nur noch Personen publiziert werden, die über einen MedRegEintrag verfügen.

Am 19. September 2019 hat der ZV beschlossen, der DV und der ÄK zu empfehlen, die FMH-Statuten so anzupassen, dass nur noch Personen, die über einen MedReg-Eintrag verfügen, Mitglied der FMH sein dürfen. Ausgenommen sind Mitglieder, die 80-jährig und älter sind. Die DV vom 29. Januar 2020 empfiehlt der ÄK, der Anpassung der FMH-Statuten zuzustimmen.

Antrag:

Die ÄK beschliesst, die FMH-Statuten wie folgt (Änderungen kursiv) anzupassen.

Art. 5 Ordentliche Mitglieder

${ }^{1}$ Als ordentliche Mitglieder werden Ärztinnen und Ärzte aufgenommen, die
- als Ärztin oder Arzt im Medizinalberuferegister MedReg der Schweizerischen Eidgenossenschaft eingetragen sind und

- ein eidgenössisches oder ein gleichwertiges Arztdiplom besitzen und

[...]

1bis Ordentliche Mitglieder müssen sich bis 1.1.2021 ins Medizinalberuferegister MedReg eintragen lassen. Ausgenommen sind vor 1.1.2018 aufgenommene Mitglieder, die 80-jährig oder älter sind.

${ }^{2}$ Ordentliche Mitglieder erwerben gleichzeitig die Mitgliedschaft in der zuständigen Basisorganisation (Art. 8).

[...]

Beschluss:

Die Statutenänderung, welche eine 2/3-Mehrheit benötigt, wird mit 150 Ja, 6 Nein und 7 Enthaltungen angenommen.

\subsection{Anpassung Anhang II:}

\section{Anerkannte Fachgesellschaften}

Gabriela Lang / Stv. Leiterin Rechtsdienst präsentiert den Antrag zur Anpassung Anhang II der Statuten wie folgt: Mit der Umwandlung des privatrechtlichen Facharzttitels Neuropathologie in einen interdisziplinären Schwerpunkt verlor die Schweizerische Fachgesellschaft für Neuropathologie ein gemäss Art. 18 Statuten FMH erforderliches Anerkennungskriterium und verlor daher per 1.1.2020 ihren Status als anerkannte Fachgesellschaft gemäss Anhang II Statuten FMH mit Stimm- und Wahlrecht und damit auch die direkte Einsitznahme in der ÄK (Art. 19 Statuten FMH). Die SSNPath hat zudem mit Schreiben vom 21.1.2020 den Verzicht auf die Anerkennung als Fachgesellschaft gemäss Anhang II Statuten FMH erklärt.

Aufgrund des Verlustes des Status der Schweizerischen Gesellschaft für Neuropathologie als eine von der ÄK anerkannte Fachgesellschaft ist der Anhang II der Statuten entsprechend anzupassen und die Schweizerische Gesellschaft für Neuropathologie formell daraus zu streichen. Gemäss Art. 30 Abs. 2 lit. v Statuten beschliesst die ÄK über die Änderung der Statuten.

\section{Antrag:}

Die ÄK beschliesst die Streichung der Schweizerischen Gesellschaft für Neuropathologie aus Anhang II der Statuten FMH.

Beschluss:

Der Antrag wird mit 135 Ja, 2 Nein und 16 Enthaltungen angenommen.

9.3. Anpassung Anhang III: Mitspracheberechtigte Ärzteorganisationen ohne Stimmrecht Gabriela Lang / Stv. Leiterin Rechtsdienst führt den An- 
trag zur Anpassung Anhang III der Statuten wie folgt ein: Die formelle Streichung der SSNPath aus Anhang II der Statuten wurde im vorangehenden Traktandum angenommen. Die SSNPath hat somit aktuell in der ÄK keinen Einsitz mehr.

Mit Schreiben vom 2.3.2020 stellt die SSNPath nun den Antrag auf Anerkennung als eine in der ÄK vertretene mitsprache- und antragsberechtigte Organisation ohne Stimmrecht gemäss Art. 25 Abs. 2 Statuten, welche in Anhang III der Statuten aufgeführt sind. Da sich die SSNPath mehrheitlich aus FMH-Mitgliedern zusammensetzt, erfüllt sie das Anerkennungskriterium gemäss Art. 25 Abs. 2 Statuten FMH: Die SSNPath zählt per 18.9.2020 insgesamt 33 Mitglieder, wovon 19 FMH-Mitglieder sind. Antrag:

Die ÄK beschliesst, den Antrag der Schweizerischen Gesellschaft für Neuropathologie vom 2.3.2020 - den die DV unterstützt - auf Anerkennung als eine in der ÄK vertretene mitsprache- und antragsberechtigte Organisation ohne Stimm- und Wahlrecht gemäss Art. 25 Abs. 2 und Anhang III der Statuten FMH anzunehmen.

Beschluss:

Der Antrag wird mit 113 Ja, 29 Nein und 18 Enthaltungen angenommen.

9.4. Anpassung Art. 7a: Wahrung der ärztlichen Berufspflichten in Unternehmen für medizinische Dienstleistungen

Franco Denti / Ordine dei Medici del Canton Ticino, OMCT erläutert die Statutenänderung Art. 7a wie folgt: Gemäss Rechtsprechung des Bundesgerichts setzt die Organisation einer Anwaltskanzlei mit angestellten Rechtsanwälten voraus, dass nur im Anwaltsregister eingetragene Anwälte eine Kanzlei besitzen und führen dürfen. Damit soll die Einhaltung der Berufspflichten der Anwälte und insbesondere die Wahrung der Unabhängigkeit gewährleistet werden. Am 31. Oktober 2019 nahm die ÄK den Vorschlag der Ärztegesellschaft des Kantons Tessin an und beauftragte den Zentralvorstand, juristisch zu prüfen, ob die gleichen Einschränkungen, die für Anwälte gelten, nicht auch für Ärzte zum Tragen kommen sollten. Auf der Grundlage eines Rechtsgutachtens der Professoren Gächter und Vokinger schlug der Zentralvorstand der Delegiertenversammlung vor, in das MedBG oder in kantonale Gesetze Mindestanforderungen aufzunehmen, um die Einhaltung der Berufspflichten und die Rechtssicherheit zu gewährleisten. Allerdings wurden dabei nicht die gleichen Einschränkungen vorgeschlagen, die für Anwälte gelten. Am 17. Juni 2020 billigte die Delegiertenversammlung mit grosser Mehrheit die Vorschläge. Die Ärztegesellschaft des Kantons Tessin (Ordine dei Medici del Canton Ticino, OMCT) ist mit dem nach ihrem Vorschlag eingeleiteten Verfahrensweg einverstanden. Allerdings ist der Ordine der Meinung, dass im Bemühen um Einheitlichkeit dieselben Prinzipien, die im MedBG und in den kantonalen Gesetzen festgehalten werden sollen, auch in die FMH-Statuten aufgenommen werden sollten.

Änderungsvorschlag: «Art. 7a Arztpraxen von ordentlichen Mitgliedern als juristische Personen:

Ordentliche Mitglieder können ihre als juristische Person organisierte Arztpraxis der FMH anschliessen, wenn die Eigentumsrechte mehrheitlich und die strategische und operative Führung ausschliesslich in ihren Händen liegen. Die Unternehmen sind so zu organisieren, dass die Ärztinnen und Ärzte, die ihren Beruf in eigener fachlicher Verantwortung ausüben, die Berufspflichten nach Art. 40 MedBG befolgen können. Insbesondere müssen die Ärztinnen und Ärzte bei medizinischen Entscheidungen frei und weisungsungebunden sein.»

\section{Antrag:}

Die ÄK beschliesst, den ZV zu beauftragen, die untenstehende fett gedruckte Anpassung des Art. 7a der FMH-Statuten vorzunehmen:

Art. 7a «Arztpraxen von ordentlichen Mitgliedern als juristische Personen

Ordentliche Mitglieder können ihre als juristische Person organisierte Arztpraxis der FMH anschliessen, wenn die Eigentumsrechte mehrheitlich und die strategische und operative Führung ausschliesslich in ihren Händen liegen. Die Unternehmen sind so zu organisieren, dass die Ärztinnen und Ärzte, die ihren Beruf in eigener fachlicher Verantwortung ausüben, die Berufspflichten nach Art. 40 MedBG befolgen können. Insbesondere müssen die Ärztinnen und Ärzte bei medizinischen Entscheidungen frei und weisungsungebunden sein.» Beschluss:

Der Antrag wird mit 132 Ja, 5 Nein und 18 Enthaltungen angenommen.

Der Vorsitzende sowie die Generalsekretärin bedanken sich bei den Mitarbeitenden des Generalsekretariats für deren äusserst kurzfristig angesagten Grosseinsatz, durch den die Durchführung dieser virtuellen Tagung überhaupt ermöglicht wurde. Die Delegierten bekräftigen den Dank mit grossem Applaus.

Jürg Schlup / Präsident FMH erklärt den heutigen ersten Sitzungstag für geschlossen und wünscht allen einen ruhigen Abend.

\section{Donnerstag, 29. Oktober 2020}

Nach Erreichen des Quorums begrüsst Jürg Schlup / Präsident FMH die Delegierten zum zweiten Tag der ÄK. 
Er bedankt sich ganz herzlich bei allen involvierten Mitarbeitenden der FMH und insbesondere bei der ICT-Abteilung unter Dominik Kreuter und den Technikteams von BERNEXPO und Kilchenmann, beim Rechtsdienst unter Ursina Pally, beim Zentralsekretariat unter Nicole Furgler sowie bei der Kommunikation unter Charlotte Schweizer und beim Zentralvorstand, die alle mit viel Know-how und enormem Einsatz innert zwei Arbeitstagen diese virtuelle ÄK auf die Beine gestellt haben. Ursina Pally Hofmann / Generalsekretärin FMH und Leiterin Rechtsdienst gibt die üblichen organisatorischen Mitteilungen und weist darauf hin, dass dieselben Regeln gelten wie an der ÄK-Sitzung vom Vortag; insbesondere gilt der für beide Tage beschlossene Ordnungsantrag, dass sofern nicht mehr als zwei Delegierte ein technisches Problem haben, die Abstimmungen und Wahlen gültig sind.

Die Sitzung beginnt mit einer Probeabstimmung und anschliessend wird das Büro bestellt. Dieses besteht aus dem Präsidenten, den Vizepräsidenten und der Generalsekretärin. Julien Duruz / Rechtsdienst FMH und Dominik Kreuter / Abteilungsleiter ICT bilden die Co-Leitung des Wahlbüros; Anne-Sylvie Thiébaud / Verantwortliche für die eidgenössische Standeskommission unterstützt diese als Stellvertreterin. Als Stimmenzähler schlägt Jürg Schlup / Präsident FMH Dr. Rudolf Ott und Dr. iur. Caroline Hartmann vor.

\section{Stimmenzählende}

Antrag:

Genehmigung der Stimmenzählenden

Beschluss:

Die Stimmenzählenden werden mit 155 Ja, 1 Nein und 0 Enthaltung gewählt.

Gemäss Art. 11, Abs. 3 GO legt die ÄK zu Beginn jeder Sitzung den Zeitpunkt fest, nach dessen Ablauf weder Beschlüsse gefasst noch Wahlen vollzogen werden dürfen. Der Präsident schlägt als Tagungsende 17.30 Uhr vor.

Antrag Festlegung Tagungsende:

Als Tagungsende wird 17.30 Uhr festgelegt. Nach 17.30 Uhr dürfen weder Beschlüsse gefasst noch Wahlen vollzogen werden.

Beschluss:

Das Tagungsende wird mit 139 Ja, 5 Nein und 4 Enthaltungen angenommen.

Jürg Schlup / Präsident FMH hält fest, dass die am Vortag beschlossene Redezeitbeschränkung von zwei Minuten für beide Tage festgelegt wurde. Diese Redezeitbeschränkung gilt für alle Delegierten, ausser den Präsidenten der angeschlossenen Organisationen. Dann weist er darauf hin, dass Anträge nur schriftlich eingereicht werden können gemäss Artikel 11 Absatz 5 der Geschäftsordnung.

\section{Wahrung der ärztlichen Berufs- pflichten in Unternehmen für medizinische Dienstleistungen}

Ursina Pally Hofmann / Generalsekretärin FMH nimmt Bezug auf die am Vortag beschlossene Ergänzung der Statuten Artikel 7a betreffend freie und weisungsungebundene Entscheidung von angestellten, in eigener fachlicher Verantwortung tätigen Ärzte.

Ursina Pally Hofmann / Generalsekretärin FMH hat ein entsprechendes Rechtsgutachten eingeholt und analysiert. Dieses kommt zusammengefasst zum Schluss, dass die ärztliche Unabhängigkeit neben den anderen in Art. 40 MedBG statuierten Pflichten auch bei einer unselbständigen Tätigkeit des Arztes in eigener fachlicher Verantwortung gewährleistet sein muss. Es wird empfohlen, Minimalstandards ins Gesetz aufzunehmen, welche sicherstellen, dass die Einhaltung der Berufspflichten gewährleistet werden kann und dass diesbezüglich Rechtssicherheit herrscht. Diese Minimalstandards können entweder auf Bundesebene im MedBG und/oder auf kantonaler Ebene gesetzlich implementiert werden.

\section{Antrag:}

Die ÄK entscheidet

1. den ZV zu beauftragen, sich um die folgenden gesetzlichen Änderungen zu bemühen:

Das MedBG sei wie folgt zu ergänzen:

«Art. 40a Unternehmen, welche Ärztinnen und Ärzte beschäftigen

Die Unternehmen sind so zu organisieren, dass die Ärztinnen und Ärzte, die ihren Beruf in eigener fachlicher Verantwortung ausüben, die Berufspflichten nach Art. 40 befolgen können. Insbesondere müssen die Ärztinnen und Ärzte bei medizinischen Entscheidungen frei und weisungsungebunden sein.» und

2. die ärztlichen Kantonalgesellschaften zu motivieren, sich um die Einführung der Grundlagen gemäss obenstehendem Art. 40a MedBG als Bewilligungsvoraussetzungen in ihren kantonalen Gesetzen zu bemühen. Beschluss:

Der Antrag wird mit 150 Ja, 4 Nein und 10 Enthaltungen angenommen.

\section{Interprofessionalität: zukünftige Entwicklungen (Physician Associate PAs)}

Jürg Schlup / Präsident FMH begrüsst Prof. Dr. med. Stefan Breitenstein, Präsident SGC und Direktor Departement Chirurgie am Kantonsspital Winterthur, der wie folgt über seine Erfahrungen mit Physician Associates berichtet: 


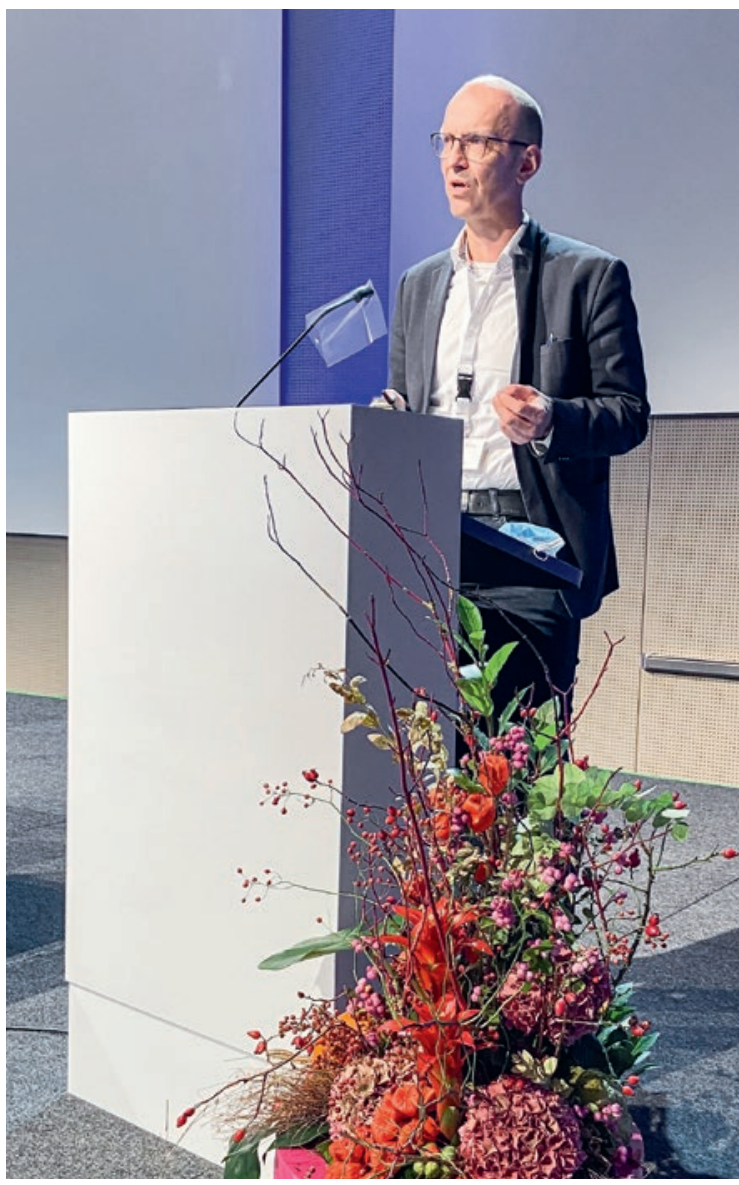

Gastredner, Prof. Stefan Breitenstein, referiert zum Thema Interprofessionalität: künftige Entwicklungen der Physician Associates.

Ein Teil des ärztlichen Arbeitsspektrums kann an Physician Associates delegiert werden. Ziel ist, die Kontinuität der medizinischen Betreuung zu verbessern. Mit dem Einsatz von PAs können die klinischen und organisatorischen Abläufe verbessert und dadurch die ärztlichen Ressourcen auf den Abteilungen optimiert werden. Die jungen Ärztinnen und Ärzte können sich vermehrt auf die Kerninhalte ihrer ärztlichen Weiterbildung fokussieren, da sie durch den Wegfall eines Grossteils der administrativen Aufgaben entlastet werden. Eine PA kann im Auftrag und in ärztlicher Delegation (unter juristisch geklärten Voraussetzungen) diagnostische und therapeutische Massnahmen durchführen.

Diagnose- und Indikationsstellung, Therapiehoheit und die Gesamtverantwortung für den Behandlungsprozess sind und bleiben Aufgaben des Arztes. Das Tätigkeitsprofil der PAs ist auf den tatsächlichen Versorgungsbedarf, die Erfordernisse des Arbeitsmarktes und die Zielvorstellungen eines ärztlich geleiteten multiprofessionellen Teams ausgerichtet.

Der Studiengang zum Physician Associate mit Bachelorabschluss bietet zudem eine weitere berufliche Ent- wicklungsmöglichkeit für Gesundheitsberufe an. Für die praktische Ausbildung werden von den Hochschulen operationalisierte Lern- und Kompetenzziele vorgegeben. Als Praxisausbildner sind die Fachärzte vorgesehen.

Nach mehreren beantworteten Präzisierungsfragen stellt der Präsident den Ordnungsantrag auf Abschluss der Rednerliste.

\section{Antrag:}

Abschluss der Rednerliste

Beschluss:

Der Ordnungsantrag wird mit $82 \mathrm{Ja}, 72$ Nein und 10 Enthaltungen angenommen.

Jürg Schlup / Präsident FMH informiert, dass der ZV das Delegationsmodell «Physician Associate», welches die FMH gemeinsam mit dem KSW erarbeitet hat, unterstützt und beantragt, dass die ÄK zur Entwicklung dieses Berufes in der Schweiz beiträgt.

\section{Antrag 1:}

Die ÄK beschliesst die Schaffung eines «Büro Physician Associates / Klinische Fachspezialisten" zur Entwicklung und Steuerung der Berufsentwicklung in der Schweiz sowie als Bindeglied zu Interessengruppen, Institutionen und Hochschulen, analog dem Büro MPA.

Beschluss:

Der Antrag wird mit 133 Ja, 21 Nein und 8 Enthaltungen angenommen.

\section{Antrag 2:}

Die ÄK beschliesst, die Anforderungen an die Ausund Weiterbildung von Klinischen Fachspezialisten / Physician Associates BSc gemeinsam mit den betroffenen Fachgesellschaften und dem vsao zu definieren.

\section{Beschluss:}

Der Antrag wird mit 136 Ja, 19 Nein und 10 Enthaltungen angenommen.

\section{Antrag 3:}

Die ÄK beschliesst, die Qualitätskriterien für die Durchführung von entsprechenden Studiengängen gemeinsam mit den betroffenen Fachgesellschaften zu definieren.

\section{Beschluss:}

Der Antrag wird mit 145 Ja, 10 Nein und 8 Enthaltungen angenommen.

\section{Antrag 4:}

Die ÄK beschliesst, den Tätigkeitsrahmen und das Delegationsprinzip für Physician Associates zu definieren. Dabei ist gemeinsam mit dem vsao in geeigneter Form sicherzustellen, dass die Einführung von Physician Associates keine negativen Auswirkungen 
auf die ärztliche Weiterbildung und die Tätigkeit von Assistenzärztinnen und -ärzten hat.

Beschluss:

Der Antrag wird mit 139 Ja, 9 Nein und 8 Enthaltungen angenommen.

\section{Antrag 5:}

Die ÄK beschliesst, dass Physician Associates künftig als ausserordentliche Mitglieder ohne Stimm- und Wahlrecht der FMH beitreten können:

- Die ÄK beschliesst, die Statuten (Art. 6 Abs. 1bis) und GO (Art. 5 Abs. 1bis und Anhang I) wie folgt zu ergänzen:

- Ergänzung Art. 6 der Statuten, Ausserordentliche Mitglieder:

1bis Physician Associates können der FMH als ausserordentliche Mitglieder ohne Stimm- und Wahlrecht beitreten.

- Ergänzung Art. 5 der GO, Ausserordentliche Mitglieder:

1bis Physician Associates richten ihr Aufnahmegesuch direkt an das GS. Das GS kann bei ausländischen Diplomen die Zustellung des Originals verlangen.

- Ergänzung Anhang I der GO, Beitragskategorien: 10bis Physician Associates als ausserordentliche Mitglieder 1/5 Beitrag

- Absichtserklärung betreffend Anhang III, Mitspracheberechtigte Ärzteorganisationen (Art. 25 Abs. 2 der Statuten):

Falls in Zukunft ein Aufnahmegesuch einer einzigen nationalen Berufsorganisation der Physician Associates (Statuten Anhang III mit Diskussions- und Antragsrecht, aber ohne Stimm- und Wahlrecht) gestellt werden sollte, ist dieses Gesuch zu prüfen.

Beschluss:

Der Antrag wird mit 70 Ja, 76 Nein und 17 Enthaltungen abgelehnt.

Jürg Schlup / Präsident FMH bestätigt, dass vier der fünf Anträge angenommen wurden. Er bedankt sich bei Prof. Stefan Breitenstein für sein Referat und sein Engagement.

\section{Unterstützungsbeitrag an Dritte: Tox Info Suisse}

Jürg Schlup / Präsident FMH führt ins Traktandum ein und begrüsst Dr. med. Joseph Widler, Präsident AGZ, der seine Interessenbindung wie folgt offenlegt:

Josef Widler ist Mitglied des Stiftungsrates von Tox Info Suisse. Diese Stiftung ist die offizielle Informationsstelle der Schweiz für alle Fragen rund um Vergif- tungen für die Bevölkerung und medizinische Fachpersonen.

Mit Beschluss der ÄK vom Oktober 2015 wurde der jährliche Trägerschaftsbeitrag der FMH an Tox Info Suisse in der Höhe von CHF 120000 im Rahmen der Budgetstabilisierungsmassnahmen gestrichen. Einzelne kantonale Ärztegesellschaften (AR/AI, BE, BS, FR, GL, GR, JU, LU, SG, SH, SO, TG, UR, VS, ZH) haben seither die Stiftung Tox Info Suisse aus eigenen Mitteln weiterhin unterstützt. Mit-Träger von Tox Info Suisse sind zurzeit neben diesen kantonalen Ärztegesellschaften auch pharmasuisse (Schweizer Apothekerverband), santésuisse (Branchenorganisation der Schweizer Krankenversicherer) und scienceindustries (Wirtschaftsverband Chemie Pharma Life Sciences) sowie die suva. Durch Leistungsverträge unterstützen GDK, BAG, $\mathrm{H}+$ und swissmedic die Angebote.

Die Leistungen der Stiftung Tox Info Suisse sind der öffentlichen Aufgabe der Notfallversorgung der Bevölkerung zuzuordnen, und es ist daher anzustreben, dass diese Notfalldienstleistungen von der öffentlichen Hand finanziert werden. Aus diesem Grund verhandelt Tox Info Suisse zurzeit auch eine neue Finanzierungslösung mit dem Bund und den Kantonen. Bis es dazu kommt, will der Antragsteller die bisherigen finanziellen Unterstützungsbeiträge einzelner kantonaler Ärztegesellschaften durch Unterstützungsbeiträge der FMH ablösen. Nach längeren Diskussionen wird festgestellt, dass der von Josef Widler schriftlich eingereichte Antrag seines Rundschreibens nicht identisch ist mit dem projizierten Antrag von Josef Widler. Josef Widler bestätigt, dass somit nicht über den Antrag, der an alle Delegierten mit Rundschreiben versandt wurde, sondern über untenstehenden Antrag abgestimmt werden soll, den er in seiner Präsentation für alle Teilnehmer sichtbar projiziert.

Antrag:

Die FMH unterstützt die Tox Info Suisse in den kommenden drei Jahren mit einem jährlichen Beitrag von CHF 120000.

Beschluss:

Der Antrag wird mit 78 Ja, 64 Nein und 9 Enthaltungen angenommen.

\section{3. Änderung in der Geschäftsordnung}

Es sind keine Anträge zu diesem Traktandum eingegangen.

\section{4. Änderung in der Standesordnung}

14.1. Einführung Art. 50

«Label responsible practice» 
Jürg Schlup / Präsident FMH begrüsst Esther Kraft / Abteilungsleiterin Departement Daten, Demographie und Qualität, welche die Ausgangfragen, die zur Formulierung des Verhaltenskodex Label «responsible practice FMH» und der entsprechenden Änderung der Standesordnung führten, aufzeigt.

- Wie geht die FMH als ärztliche Organisation mit der zunehmenden Zahl nicht ärztlich geführter Unternehmen um, in denen ein wachsender Anteil unserer Mitglieder oder auch Nicht-Mitglieder sich anstellen lässt?

- Wie kann die FMH sicherstellen, dass sie auch in Zukunft die standesrechtlichen Normen Mitgliedern gegenüber durchsetzen kann, die zwar fachlich selbständig, aber wirtschaftlich unselbständig erwerbstätig sind und vom Arbeitgeber unter Druck gesetzt werden können, sich nicht an die Standesregeln zu halten?

Der ZV der FMH und die DV der FMH haben dafür nach erfolgreicher Durchführung eines Pilotprojekts mit zehn Arztpraxen - die Einführung des Labels «responsible practice FMH» gutgeheissen. Das Label «responsible practice FMH» soll 2021 mit folgenden Zielen eingeführt werden:

- Die Patientinnen und Patienten sollen wissen, in welchen Einrichtungen der medizinischen Versorgung die Standesordnung der FMH Richtschnur für ärztliches Handeln ist.

- Überprüfung der wesentlichen Forderungen der Standesordnung in Form einer Selbstdeklaration und in Stichproben durch ein Audit vor Ort

- Nach erfolgreich bestandener Prüfung wird die Organisation/Praxis mit dem Label «responsible practice FMH» ausgezeichnet.

In der aktuellen Standesordnung ist die Vergabe eines Labels nicht vorgesehen. Das heisst: die vertraulich arbeitende Standeskommission darf die Organe des Labels aktuell nicht auf eine Verletzung der Standesordnung aufmerksam machen. Somit besteht die Möglichkeit, dass eine Praxis, eine Einrichtung Inhaberin dieses Labels ist und eine dort tätige Ärztin oder ein dort tätiger Arzt wegen Verletzung der Standesordnung sanktioniert wird. Entsprechend schlägt der Zentralvorstand der ÄK vor, die Standesordnung anzupassen, damit diese Möglichkeit nicht besteht.

Antrag:

Die ÄK beschliesst die Anpassung der Standesordnung - mit neuem Art. 50 StaO Label «responsible practice $F M H »-$ wie folgt:

Ist die Praxis oder Organisation, in welcher die sanktionierte Ärztin oder der sanktionierte Arzt tätig ist, Inhaberin des Labels "responsible practice FMH", so wird der Entscheid der für das Label zuständigen
Geschäftsstelle der FMH zugestellt. Diese Zustellung ist optional, wenn die ausgesprochene Sanktion in einem Verweis oder einer Busse bis CHF 1000 besteht.

Beschluss:

Der Antrag wird mit 122 Ja, 15 Nein und 12 Enthaltungen angenommen.

\section{Budget 2021}

\subsection{Budget SIWF 2021}

Christoph Hänggeli / Geschäftsführer SIWF informiert, dass das SIWF sich hauptsächlich über die Einnahmen der Facharzttitel finanziert, welche grossen Schwankungen unterliegen, so dass es nicht einfach ist, Prognosen zu stellen. 2019 wurden beispielsweise 100 Titel weniger erteilt als im Vorjahr. Trotzdem geht das SIWF aufgrund der steigenden Zahl Assistenzärztinnen und Assistenzärzte und der gleichbleibend hohen Anzahl anerkannter ausländischer Arztdiplome für das Budget 2021 davon aus, dass die Einnahmen von erteilten Facharzttiteln um eine halbe Million zunehmen werden. Ungewiss sind die Auswirkungen der Pandemie auf die Rechnung 2020 und das Budget 2021. Unzählige Spezialregelungen in 134 Fachgebieten verursachen einen riesigen Aufwand und führen zu Rückständen bei der Bearbeitung von Titelgesuchen. Auch können viele Visitationen nicht durchgeführt werden, was zu einem nicht unwesentlichen Einbruch bei den Einnahmen führen wird.

Konkret rechnet das SIWF mit einem ausgeglichenen Budget (Gewinn: CHF 4000).

Für die weitere Finanzplanung in den nächsten Jahren sind zurzeit keine grossen Veränderungen vorauszusehen. Christoph Hänggeli / Geschäftsführer SIWF erinnert zum Schluss daran, dass das SIWF seit zwanzig Jahren eidgenössische Facharzttitel erteilt und die Gebühr erfreulicherweise immer noch unverändert CHF 4000 beträgt.

\subsection{Budget 2021 FMH}

Patrick Egger / Leiter Abteilung Finanzen und Verwaltung, Stv. Generalsekretär informiert, dass die FMH für das Jahr 2021 einen Verlust von CHF 2,045 Mio. budgetiert. Die Ausgabenbremse, welche die Ausgaben des Budgets mit den Einnahmen der letzten Jahresrech nung vergleicht, wird eingehalten. Das SIWF budgetiert einen Gewinn von CHF 0,004 Mio. Konsolidiert weist das Budget einen Verlust von CHF 2,041 Mio. aus. Wesentliche Ertragsabweichungen: Bei den Mitgliederbeiträgen wird in Zukunft ein Ertragsrückgang von CHF 0,700 Mio. im Vergleich zum Budget 2020 erwartet, was in etwa den Werten des Rechnungsjahres 2019 
entspricht. Dies ist auf demographische Veränderungen zurückzuführen. Im Jahr 2021 ist geplant, Rückstellungen aufzulösen, hauptsächlich für die Sanierung der Elfenstrasse.

Wesentliche Aufwandsabweichungen: Der direkte Aufwand wird sich unter anderem erhöhen, da aufgrund der Covid-19-Situation für die DV und die ÄK grössere Lokale gemietet werden müssen. Der Lohnaufwand erhöht sich nur geringfügig. Der Grund hierfür ist, dass auf allgemeine Lohnerhöhungen und Anpassung an die Teuerung aufgrund der Covid-19-Situation mit Rücksicht auf die teilweise schwierige Situation für die Ärzteschaft verzichtet wird. Wesentliche Mehrkosten ergeben sich aus der Sanierung der Elfenstrasse und aus den Kosten für die Ersatzliegenschaft an der Nussbaumstrasse. Dabei handelt es sich bei der Elfenstrasse um werterhaltende und wertvermehrende Kosten. Insgesamt werden CHF 5,814 Mio. Rückstellungen für die Sanierung der Elfenstrasse aufgelöst. Die Kosten des Ersatzstandortes an der Nussbaumstrasse von CHF 0,706 Mio. gehen zulasten der Erfolgsrechnung.

\subsection{Budget $2021 \mathrm{GPK}$}

Patrick Egger / Leiter Abteilung Finanzen und Verwaltung, Stv. Generalsekretär informiert, dass das Budget 2021 der Geschäftsprüfungskommission mit Totalkosten von CHF 0,088 Mio. schlanker ist als im Jahr 2020 geplant. Der Grund für höher geplante Ausgaben im Jahr 2020 ist die Wahl von neuen Mitgliedern in die GPK. Mit der Übergabe der Dossiers wurden zusätzliche Sitzungen geplant.

\subsection{Bericht GPK}

Jürg Schlup / Präsident FMH begrüsst Philippe Vuillemin / neu gewählter Präsident GPK, der über die Sitzungstätigkeit im vergangenen Jahr rapportiert. Er stellt den im konsolidierten Budget FMH ausgewiesenen Verlust von TCHF 2041 fest.

Die derzeit offenen Stellen bei FMH/SIWF müssen noch besetzt werden. Die Umbaukosten der Liegenschaft an
Grundbeitrag 2021 CHF 710

$1 \quad$ Praktizierende Ärztinnen und Ärzte $\quad$ CHF 710

\begin{tabular}{lll}
2 & Leitende Spitalärztinnen und -ärzte & CHF 710 \\
\hline 3 & $\operatorname{Im}$ Spital tätige Oberärztinnen und -ärzte und Spitalfachärztinnen & CHF 475
\end{tabular} und -ärzte

$4 \quad$ Ärztinnen und Ärzte in Weiterbildung zu einem Facharzttitel oder $\quad$ CHF 355 Schwerpunkt

$5 \quad$ Wohnsitz und Berufstätigkeit im Ausland $\quad$ CHF 284

$6 \quad$ Vorübergehend nicht als Ärztin/Arzt berufstätige Mitglieder $\quad$ CHF 178

$7 \quad$ Nach Berufsaufgabe (z.B. aus Altersgründen) $\quad$ CHF 142 der Elfenstrasse 18 und die Miete für den Ersatzstandort an der Nussbaumstrasse 29 belasten das Budget 2021. Trotz der Unsicherheiten durch die Pandemie rechnet das SIWF mit ausreichenden Weiterbildungsund Akkreditierungsaktivitäten.

\section{Budget FMH}

- Die Kosten für die Renovation der Liegenschaft Elfenstrasse 18 sind unter Kontrolle.

- Die Kosten der IT-Governance (I-Governance/GEVER) könnten im Budget noch für Überraschungen sorgen.

- TARCO; Versicherungspolitik; Pandemie; Bundesrat und Bundesversammlung; Beziehungen zu den Medien - dies sind die Dauerbaustellen, die ein erhebliches Engagement der FMH erfordern und jederzeit zusätzliche Budgetausgaben nach sich ziehen können.

- Das Defizit erklärt sich durch diese drei vorgenannten Punkte und ist nicht auf strukturelle Probleme der FMH zurückzuführen. Die Finanzplanung bleibt unter Kontrolle.

\section{Budget SIWF}

- Die Facharztakkreditierungen dürften wieder das Niveau von 2014 erreichen (+ CHF 550 000).

- Bei der Weiterbildungsplattform wird ein Einnahmenüberschuss von CHF 50000 erwartet.

- Die wichtigsten Ausgabenfaktoren sind die Verbesserung der Weiterbildungsplattform und ihre Digitalisierung, interne Verrechnungen und die Aufstockung des Personals.

Anlagestrategie

- Die Liquidität ist ausgezeichnet.

- Die Anlagerenditen sind deutlich besser als die Pandemie es hätte vermuten lassen.

Budgetstabilisierung: Die Vorgaben zur Erreichung der Budgetstabilisierung sind erfüllt.

Empfehlung: Die GPK beantragt somit die Genehmigung der Budgets $2021 \mathrm{FMH}$, SIWF und GPK sowie des konsolidierten Budgets 2021 und die erneute Beauftragung von BDO als Revisionsstelle für eine Amtszeit von zwei Jahren.

\subsection{Mitgliederbeiträge 2021}

\section{a) Grundbeitrag für 2021}

Patrick Egger / Leiter Abteilung Finanzen und Verwaltung, Stv. Generalsekretär informiert, dass der Grundbeitrag für 2021 gemäss Antrag des ZV und der GPK folgende Beträge beinhaltet (siehe Tabelle links):

\subsubsection{Antrag Eggimann, SVM: Senkung der FMH-Mitgliederbeiträge}

Jürg Schlup / Präsident FMH informiert, dass zum Antrag auf Senkung der FMH-Mitgliederbeiträge von Phi- 
lippe Eggimann / Präsident SMSR heute untenstehender Antrag auf Nicht-Eintreten von Thomas Eggimann / $S G G G$ eingereicht wurde. Es folgt eine längere Diskussion.

Antrag auf Nicht-Eintreten:

Die ÄK beschliesst, auf den Antrag von Philippe Eggimann 2020_10_15.5.1 nicht einzutreten.

Beschluss:

Der Antrag auf Nicht-Eintreten wird mit 88 Ja, 53 Nein und 12 Enthaltungen angenommen.

Antrag:

Die ÄK genehmigt die Grundbeiträge 2021: Kat. 1 und 2 = CHF 710.-, Kat. 3 = CHF 475.-, Kat. 4 = CHF 355.-, Kat. 5 = 284.-, Kat. 6 = CHF 178. - , Kat. 7 = CHF 142.- . Beschluss:

Die Grundbeiträge gemäss Antrag ZV und unterstützt von DV sowie GPK werden mit 140 Ja, 6 Nein und 4 Enthaltungen angenommen.

\section{b) Antrag NAKO}

Antrag:

Die ÄK genehmigt den Sonderbeitrag 2021 zugunsten NAKO (Nationale Konsolidierungsstelle) von CHF 40 für die Kategorien 1 und 2.

Beschluss:

Der Antrag wird mit 115 Ja, 12 Nein und 21 Enthaltungen angenommen.

\section{c) Antrag Revue Médicale Suisse}

Antrag:

Die ÄK genehmigt den Sonderbeitrag 2021 zugunsten "Revue Médicale Suisse» von CHF 10 für die Kategorien 1, 2, 3, 5 und 6.

Beschluss:

Der Antrag wird mit 117 Ja, 21 Nein und 13 Enthaltungen angenommen.

\subsection{Budget 2021 konsolidiert}

Antrag:

Die ÄK verabschiedet das konsolidierte Budget 2021

der FMH mit einem Verlust von CHF 2,041 Mio.

Beschluss:

Das konsolidierte Budget wird mit 132 Ja, 9 Nein und 13 Enthaltungen angenommen.

\section{Verabschiedungen}

Jürg Schlup / Präsident FMH informiert, dass dieses Jahr insgesamt sechs verdiente Persönlichkeiten verabschiedet werden müssen. Er beginnt mit der Laudatio für Werner Bauer / Präsident SIWF.

Wer wie Werner auf eine so lange ärztliche und standespolitische Karriere zurückblicken kann, und wer während seiner Laufbahn so viele Ideen und Projekte vorangetrieben hat, macht eine Laudatio zur anspruchsvollen Herausforderung.

Als du Präsident des Kollegiums für Hausarztmedizin warst, sagtest du das Ziel deiner standespolitischen Tätigkeit sei, den Ärzten «die Freude am Beruf als Voraussetzung für eine qualitativ gute Arbeit zu erhalten». Die Freude als Voraussetzung für Qualität hast du in den Folgejahren nie aus den Augen verloren. Als du 2009 zum SIWF-Präsidenten gewählt wurdest - nach überraschender Spontankandidatur -, hobst du «die Weiter- und Fortbildung als Kernaufgabe der ärztlichen Berufspolitik» hervor, die verschiedene Anliegen berücksichtigen müsse: «strukturierte Weiterbildungsgänge für die junge Generation, Anforderungen von Patienten und Öffentlichkeit, Förderung einer hohen Arbeitsqualität und Vermeiden von Überregulierungen». Besonders fördern wolltest du das "Teaching» in der Tradition der "Colleges of Physicians», das nicht nur Kompetenzen, sondern auch «Begeisterung für den Arztberuf vermitteln» soll. Auf die Schwierigkeiten dabei hast du immer wieder hingewiesen: Zunehmend enger gesteckte «ökonomische und tarifliche Rahmenbedingungen, die Anforderungen an Produktivität und Effizienz, die knappen personellen Ressourcen und die administrative Belastung» führen häufig dazu, dass die Zeit für die Weiterbildung als Erstes leidet. Umso wichtiger war dein Engagement für das Teaching, z.B. durch helvetisierte Teach-the-teacher-Workshops und durch Prämierungen von Projekten und engagierten Weiterbildnern, die der jüngeren Generation trotz aller Schwierigkeiten «Kenntnisse, Fähigkeiten, Berufsfreude und Haltung vermitteln".

Durch Aktivitäten wie diese oder auch durch die Einführung des MedEd-Symposiums für alle in der Weiterbildung Engagierten hast du die Weiter- und Fortbildung gestärkt, bist zu ihrem Botschafter geworden und konntest bei den Behörden und zwischen den Fachgesellschaften vermitteln. Durch deinen internationalen Blick und dein Interesse an den aktuellsten Entwicklungen wurden unter deiner SIWF-Präsidentschaft neueste Methoden verfolgt und integriert (ein Beispiel dafür sind die EPAs). Aber auch die Umsetzung schwieriger Projekte im operativen Alltag - wie das Zustandebringen eines funktionierenden e-Logbuchs und einer funktionierenden Fortbildungs-Plattform konntest du erfolgreich vorantreiben.

Und weil - wie du selbst sagtest - «eigentlich fast alles schon einmal gesagt wurde», werde ich nun trotzdem mit einem dir sicher vertrauten Osler-Zitat zum Schluss kommen: «Die beste Vorbereitung auf morgen ist es, die Arbeit von heute grossartig gut zu machen.» In diesem Sinne hast du als SIWF-Präsident die Weiter- 


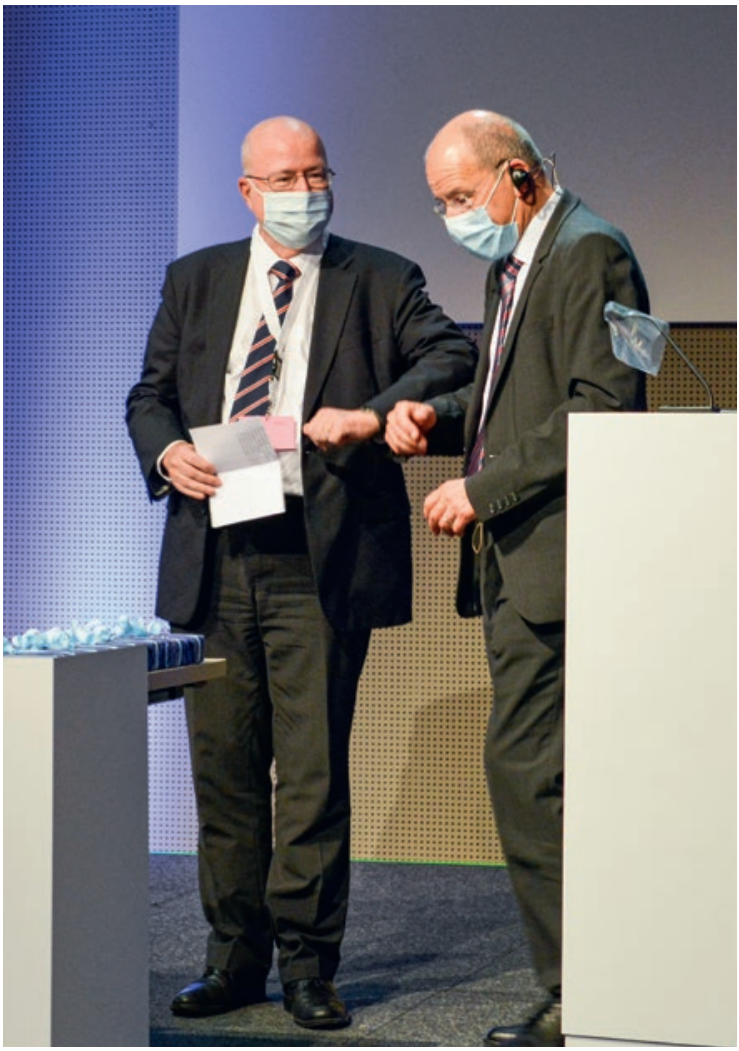

Jürg Schlup würdigt Werner Bauer, der nach 10 Jahren als Präsident des Schweizerischen Instituts für Weiter- und Fortbildung SIWF zurücktritt.

bildung der nächsten Generation unserer Berufskolleginnen und -kollegen geprägt. Auch wenn es hoffentlich noch etwas dauert, bis wir beide selber mehr Patienten als Ärzte sind, ist die Aussicht doch tröstlich, dann von einer Ärztegeneration versorgt zu werden, deren Weiterbildung von deinem Engagement geprägt wurde. Bis dahin wünsche ich dir jedoch einen wunderbaren Ruhestand, bei dem übrigens auch die Freude eine zentrale Voraussetzung für die Qualität sein dürfte. Vielen Dank!

Werner Bauer / Präsident SIWF bedankt sich für die bewegenden Worte mit folgendem Reim:

Lieber Jürg und liebe Leute, schnell eilt die Zeit. Drum gilt es heute, elf Jahre nach erfolgter Wahl, damals im Saal, nicht digital, Adieu zu sagen kurz und knapp. Man kommt, man wirkt und man tritt ab. Es passen jetzt nur ein paar schnelle Worte in Jürgs Zeittabelle. So möchte ich denn vor allem danken, ergänzt von einem Kerngedanken: heut ist aus respektablem Grunde die Qualität in aller Munde. Doch worauf gründet Qualität in jeder Spezialität? Zu raten gibt's da nicht unendlich, die Bildung ist es selbstverständlich. Dass wir in Bildung investieren, wird bald als Qualität rentieren. Drum lasst uns heute und auch morgen für beste Weiterbildung sorgen. Das war's. Was bleibt, ist Dank- barkeit für Support und Mitarbeit, die ich erfuhr in diesen Jahren, die schön und durchwegs spannend waren. Mein Wunsch, der auch noch reimen tut: zum Schluss heisst's «SIWF, mach's gut!».

Jürg Schlup / Präsident FMH verabschiedet als nächstes Adrian Sury / Präsident GPK.

Seit über 20 Jahren engagierst du dich nun schon für die FMH, seit 1997 in der Finanzkommission bzw. seit 2006 dann in der GPK und seit 2013 als deren Präsident. Durch deine lange Tätigkeit und Verbandserfahrung gibt es kaum ein Dossier der FMH, zu dem du nicht alle Hintergründe und Geschichten kennen würdest - deshalb ist eine deiner vielen positiven Eigenschaften für die FMH besonders bedeutsam: deine Integrität. Die Interna der FMH waren bei dir immer in besten Händen: dein Amtsgeheimnis war dir ebenso wichtig wie das Arztgeheimnis. Du hast dein umfassendes Wissen immer im Sinne der FMH eingesetzt, so dass die Arbeit der GPK und damit die FMH enorm davon profitieren konnten.

Aber nicht nur deine absolute Vertrauenswürdigkeit und deine Abneigung gegen Ränkespiele, sondern auch viele weitere Eigenschaften haben dich zur idealen Besetzung dieser Position gemacht. Du schaust Herausforderungen immer aus verschiedenen Blickwinkeln an und vor allem bist du sehr geduldig und kannst auch dann noch sehr konzentriert zuhören, wenn andere innerlich schon abgehängt haben.

Wen man auch fragt, du wirst immer so beschrieben, wie ich dich auch erlebt habe: als enorm einnehmende Person, die man ausnahmslos gut gelaunt in Erinnerung hat. Dadurch, dass du immer ruhig und gelassen bleibst und den Menschen wohlwollend und auch humorvoll gegenübertrittst, hast du immer einen guten Draht zu den wechselnden FMH-Exponenten gefunden. Du konntest auch unangenehme Aussagen erträglich vermitteln, den Finger auf «wunde Punkte» legen und auf diese Weise wirksam Verbesserungen anstossen. Gerade in den zwischendurch auch "turbulenten" Zeiten mit viel Mehrarbeit für die GPK haben deine Professionalität und dein menschliches Gespür sehr geholfen, auch explosive Stimmungen zu entschärfen.

Jetzt bietet sich für dich vermutlich eine Gelegenheit, dein Engagement zwischen Medizin und Musik an anderen Orten zu verstärken. In diesem Sinne wünsche ich dir für die Zeit nach der GPK alles Gute und danke dir im Namen des Vorstands und der FMH für deine langjährige, wertvolle Arbeit!

Adrian Sury / Präsident der GPK bedankt sich für diese wohlwollenden Worte und leitet sie seinen GPK-Mitgliedern weiter.

Es folgt die Verabschiedung von Thomas Kehl / GPKMitglied durch Adrian Sury / Präsident der GPK. Thomas 


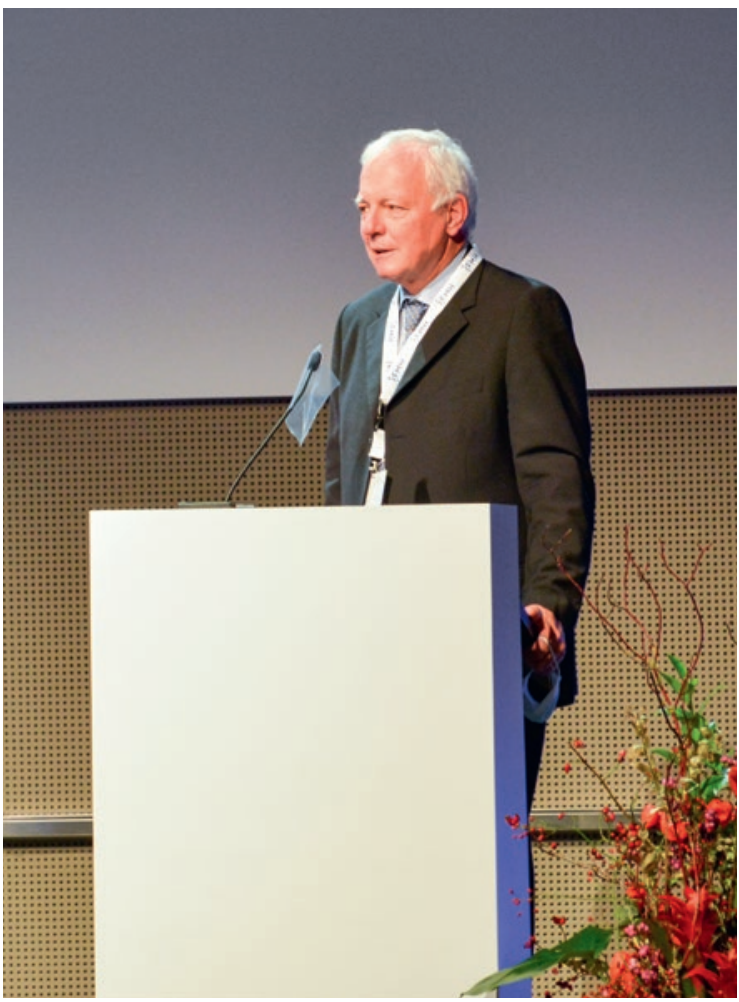

Adrian Sury, scheidender GPK-Präsident.

Kehl war einer der aktivsten Kollegen in unserem Gremium. Mit seinen Erfahrungen aus der Orthopädie/ Traumatologie, aus der Ausbildung, aus Verwaltungsräten, als CEO bei den Zürcher Reha-Zentren und von den Appenzeller Spitälern konnte er die GPK-Arbeit auf vielfältige Weise unterstützen. Er gehörte zu den Mitinitianten der Strukturreform der FMH, bevor er sein 12-jähriges Engagement in der GPK antrat. Er war ein wichtiger Berater der Taskforce «Budgetstabilisierung». Er war ein vehementer Verfechter des Zweikammer-Systems und Controller der GS-Abläufe. Nach drei Legislaturperioden tritt er zurück, wegen der Amtszeitbeschränkung und auch wegen der Altersbeschränkung. Wir werden ihn gerne in Erinnerung behalten als äusserst aktives GPK-Mitglied und wünschen ihm viel Freude in seinen Davoser Bergen und auch in seinem Ferienhaus am Vierwaldstättersee mit dem Segelschiff. Herzlichen Dank, Thomas.

Adrian Sury / Präsident GPK verabschiedet den zurücktretenden Alexander Zimmer / GPK-Mitglied. Er tritt zurück, da er für den ZV kandidiert hat. Er wurde gestern zum Mitglied des ZV gewählt - herzliche Gratulation! Er ist nach einer Chefarzt-Position im Kanton Baselland vor einigen Jahren in seine eigene Praxis nach Solothurn gezogen. Er kennt sich sehr gut aus in der stationären und ambulanten Medizin. Zudem ist er Präsident der ständigen Tarifkommission der Psychiater und war auch Mitglied der Taskforce.
Es ist wichtig, dass die GPK mit Vertretern aus allen Landesteilen sowie der Chirurgen und der Psychiater besetzt ist. Diese Pluralität erlaubt es, dass Gesichtspunkte von vielen Seiten eingebracht werden. Als Psychiater hat Alexander häufig sehr subtil auf andere Sichtweisen aufmerksam gemacht.

Er hat einen sehr feinen Charakter, sehr viel Humor, und er hat viel zum ausgezeichneten Klima in der GPK beigetragen. Zum Glück verlieren wir ihn jetzt nur in der GPK, aber ich bin überzeugt, dass er im ZV mit seinem Wissen und Gewissen sicher ausgezeichnete Arbeit leisten wird. Ich wünsche ihm alles Gute für diese neue berufliche Herausforderung.

Jürg Schlup / Präsident FMH verabschiedet als nächstes Jürg Unger / ZV-Mitglied und Departementsverantwortlicher Stationäre Versorgung \& Tarife.

Auch Jürg Unger wird seine Tätigkeit im Zentralvorstand der FMH beenden - und obwohl er dies nach nur einer Legislatur, also einer vergleichsweise kurzen Zeit von vier Jahren tut, wird sein Einsatz in dieser Zeit wohl langfristig Wirkung zeigen.

Vielleicht liegt es an seiner Verwurzelung in der Kinderpsychiatrie, dass ihm so bewusst ist, dass es für nachhaltige Veränderungen junge Menschen zu erreichen gilt. Vielleicht liegt sein Fokus auf die junge Ärztegeneration auch darin begründet, dass im Wirkungskreis seines Departements - der stationären Versorgung - die Mehrheit unserer jüngeren Mitglieder beschäftigt ist. Oder vielleicht liegt es auch an den Erfahrungen in seiner eigenen ärztlichen Karriere, in der er zuletzt als Chefarzt in der Verantwortung für seine jungen Berufskollegen und -kolleginnen stand. Zumindest ist es ihm gelungen, sein Herzensanliegen, das Projekt Coach my Career, das junge Ärztinnen und Ärzte von der Erfahrung der Älteren profitieren lassen möchte, erfolgreich aufzugleisen und für die Zukunft zu verankern. Dieses Projekt - genauso wie auch die von ihm weiterentwickelte Seminarreihe «Führung und Management im Gesundheitswesen" - fördert Ärztinnen und Ärzte in ihrer beruflichen Entwicklung, unterstützt sie darin, ihren Platz in der Versorgung zu finden und erhöht damit nicht nur die berufliche $\mathrm{Zu}$ friedenheit, sondern verbessert auch die Gesundheitsversorgung

In einem seiner Editorials schrieb Jürg Unger einmal, Menschen in Verbandsgremien müssten «eine echte Bereitschaft zur Zusammenarbeit haben und nicht von egomanen Ambitionen getrieben» sein. Sie sollten "trotz aller Unterschiedlichkeiten auf ein gemeinsames Ziel hinarbeiten", sich gegen aussen «konsistent verhalten" und "sich auch bei Unstimmigkeiten respektieren und vertrauen». Ich denke, damit hat er selbst am besten beschrieben, was wir auch im Zentral- 


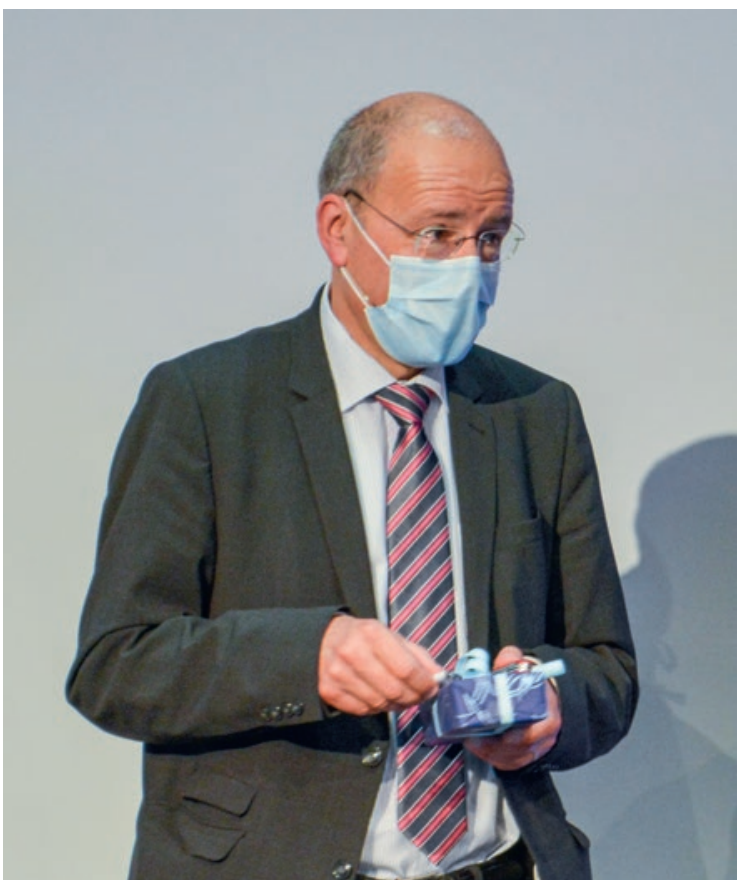

Jürg Schlup tritt nach acht Jahren als Präsident der FMH ab. Er erreichte unter anderem einen gemeinsamen Vorschlag von Ärzteschaft und Versicherern für eine Revision des ambulanten Tarifs.

vorstand an ihm immer sehr geschätzt haben. Das Kompliment, das er dem Zentralvorstand in seinem jüngsten Editorial ausgesprochen hat, dass er in «20 Jahren in Geschäftsleitungen und Verwaltungsräten nie eine so angenehme und konstruktiv lösungsorientierte Zusammenarbeit erlebt [hat] wie in diesem Zentralvorstand", kann ich ihm hier im Namen des gesamten Zentralvorstands zurückgeben.

Lieber Jürg, das Gute an deinem Abschied aus dem ZV dürfte sein, dass du als Familienmensch wieder mehr Zeit für dich, deine Liebsten und deine Hobbys haben dürftest. Wir hoffen, du kannst deine neu gewonnene Freizeit geniessen und wünschen dir alles Gute.

Christoph Bosshard / Vizepräsident FMH und Departementsverantwortlicher Daten, Demographie \& Qualität verabschiedet Jürg Schlup / Präsident FMH. Herzlichen Dank, lieber Jürg. Liebe Kolleginnen und Kollegen, eigentlich mache ich das gar nicht gerne, Jürg verabschieden. Aber es ist eine grosse Ehre, dies tun zu dürfen. Wir wissen alle, dass Jürg kein Mann der grossen Worte ist und sich gar nicht gerne im Mittelpunkt sieht.

Anstelle einer langen Rede folgt ein Film mit vielen Statements von Wegbegleitern während der achtjährigen FMH-Präsidentschaft von Jürg Schlup. Als Abschiedsgeschenk überreicht Christoph Bosshard Jürg Schlup diesen Film. Als Begleiter im nächsten Lebens- abschnitt überreicht er ihm auch ein Taschenmesser, mit wichtigen «Instrumenten», wie zum Beispiel einem Zapfenzieher, der einem immer wieder gelegen kommen kann, einem Büchsenöffner für hartnäckige, widerspenstige Dinge im Leben, einem Schraubenzieher, um Festgefahrenes zu lockern. Natürlich dürfen ein grosses und ein kleines Messer auch nicht fehlen, um die anderen Notwendigkeiten im Alltagsleben, sei es auf Wanderungen oder in Haus und Garten, bewältigen zu können. Christoph Bosshard bedankt sich ganz herzlich, auch ein Teil des Teams von Jürg Schlup gewesen sein zu dürfen.

Nach einem sehr langen Applaus richtet Jürg Schlup einen grossen herzlichen Dank an die ZV-Mitglieder an alle Delegierten sowie an alle Mitarbeitenden und wünscht der neuen Führungscrew unter der Leitung der neuen Präsidentin viel Freude und Erfolg!

\section{Tarifstruktur TARDOC - Aktueller Stand und Informationen}

Urs Stoffel / ZV-Mitglied und Departementsverantwortlicher Ambulante Versorgung \& Tarife hält Rückblick darüber, was sich seit der Einreichung der Tarifstruktur TARDOC am 12. Juli 2019 ereignet hat. Das BAG erwartete nach der Einreichung umfangreiche Zusatzunterlagen, die fristgerecht nachgereicht wurden. Nach der Sitzung vom 8. November 2019 kam per Ende Jahr die formelle Rückmeldung des BAG, dass die Tarifstruktur aus folgenden Gründen nicht genehmigungsfähig sei:

- Nicht vorhandene Mehrheit bei den Krankenversicherern

- Einreichung von zwei unterschiedlichen Tarifstrukturen (normiert und unnormiert)

- Keine Einigung der Tarifpartner betreffend die kostenneutrale Überführung von TARMED in TARDOC. Eine Vorstellung von TARDOC bei santésuisse erfolgte im Januar 2020. Zwischen Februar und April 2020 fanden drei intensive halbtägige Workshops mit dem BAG und Vertretern von curafutura, FMH und ats-tms AG statt. Das BAG hat H+ und santésuisse aufgefordert, bis Ende März 2020 mitzuteilen, weshalb sie sich nicht an TARDOC beteiligen und eine erste Einschätzung zum TARDOC abzugeben. Curafutura und FMH haben dem BAG ebenfalls eine Stellungnahme zur Koordination Pauschaltarif und Einzelleistungstarif eingereicht.

Urs Stoffel / ZV-Mitglied und Departementsverantwortlicher Ambulante Versorgung \& Tarife erläutert die Gründe, weshalb es wichtig ist, am Genehmigungsgesuch festzuhalten. Weiter informiert er, dass mit dem Beitritt von SWICA zum TARDOC die Tarifstruktur 
TARDOC nun auch von der Mehrheit der Versicherten (ca. 53\%) unterstützt wird. Anhand von Beispielen zeigt er die Modelle zur Lösung der Kostenneutralität mit Monitoringkonzept auf, das Ende Juni 2020 dem Bundesrat nachgereicht wurde. Damit sind aus Sicht der beteiligten Tarifpartner alle formellen Anforderungen an eine Genehmigung des TARDOC erfüllt. Im Juli 2020 wurde der TARDOC und das nachgereichte Kostenneutralitätskonzept auch der $\mathrm{H}+$ detailliert vorgestellt.

Ergänzend informiert er, dass ats-tms AG seit fünf Jahren eine nationale funktionierende Tariforganisation mit einer operativen Geschäftsstelle ist. Diese hat nicht nur einen neuen Tarif entwickelt, sondern auch bereits die Prozesse definiert, die für eine reibungslose Einführung des Tarifs notwendig sind. Insbesondere entwickelt die Geschäftsstelle ats-tms AG zusammen mit den Experten der Tarifpartner ein Tool (LegiData) für die Spartenanerkennung und Verwaltung der Dignitäten. Mit Freude berichtet er, dass Joachim Eder, alt Ständerat und ehemaliger Präsident der ständerätlichen Gesundheitskommission, als neuer Präsident der ats-tms AG gewonnen werden konnte.

Nach wie vor wird der bereits mehrfach in Aussicht gestellte und immer wieder verschobene Prüfbericht des BAG erwartet. Das BAG hat bisher noch keinen Zeitplan über das weitere Vorgehen vorgelegt und auch nicht aufgezeigt, wann eine Inkraftsetzung erfolgen könnte.

\section{Information zu MAS}

Christoph Bosshard / Vizepräsident FMH und Departementsverantwortlicher Daten, Demographie \& Qualität berichtet über die Datenerhebung der Strukturdaten Arztpraxen und ambulante Zentren MAS (Medical Ambulatory - Structure) des Bundesamtes für Statistik im Auftrag des Eidgenössischen Departementes des Innern gemäss Artikel 59a KVG. Die Teilnehmer-/Rücklaufquote der Erhebung 2018 hat im Vergleich zur Erhebung 2017 abgenommen, was auf die Covid-19-bedingte Situation zurückgeführt wird. Um die Arztpraxen und ambulanten Zentren in diesem Kontext zu entlasten, wurde die Erhebung der Daten 2018 frühzeitig beendet (Ende März 2020 anstatt Mitte April 2020). Dies hat zur Verringerung der Kontakt- und Antwortquote geführt.

Er präsentiert anschliessend die Grafiken mit den Aufschlüsselungen der Datenlieferungen nach Kanton und Zweck. Eine wesentliche Erkenntnis und Aussage der 2018er Zahlen besteht darin, dass 40\% der Ärztinnen und Ärzte in der medizinischen Grundversorgung (Facharztgebiete Allgemeine Innere Medizin, Pädiatrie, praktische Ärztin/ praktischer Arzt) tätig sind. Je jünger die Ärztinnen und Ärzte sind, desto höher ist der Anteil derjenigen in der medizinischen Grundversorgung. Die Ärztinnen machten bei den 35- bis 39-Jährigen $62 \%$, bei den 60 - bis 64 -Jährigen dagegen lediglich 28\% aus. Die Betriebsergebnisse der Einzelpraxen sind vergleichbar mit MAS 2015/2017.

Zusammenfassend kann festgehalten werden, dass die Ergebnisse 2018 vergleichbar sind mit den Ergebnissen 2015 und 2017 und diese somit bestätigen. Die gute und konstruktive Zusammenarbeit mit dem BFS wird weitergeführt und die "Spielregeln» bleiben für die MAS2019-Erhebung dieselben. Die MAS-Erhebung bezüglich der Daten 2019 startet am 9. November 2020 und dauert bis am 28. Februar 2021.

Die MAS-Erhebung an und für sich, deren Konstanz im Sinne der Reproduzierbarkeit der Daten, die hervorragende Teilnahmequote sowie die schliesslich vom Bund validierten Daten sind für die Ärzteschaft wichtig, auch gerade vor dem Hintergrund der Dokumentation von Entwicklungen im Kontext Covid-19.

\section{Informationen aus Zentralvorstand, Generalsekretariat, SIWF und Abtei- lungen}

Jürg Schlup / Präsident FMH informiert, dass die Delegierten die Informationen aus den Departementen mit den Sitzungsunterlagen erhalten haben.

\section{Positionierung der Schweizer Ärzteschaft zum Thema Klimawandel und Gesundheit}

Jürg Schlup / Präsident FMH begrüsst Michael Burkardt / swimsa, der sich im Namen der Schweizer Medizinstudierenden bedankt, dass die FMH mit der Unterzeichnung des Manifestes die Bemühungen zum Schutz des Klimas unterstützt.

Der Klimawandel stellt die grösste gesundheitliche Bedrohung in unserem Jahrhundert dar. Er ist schon jetzt ein medizinischer Notfall, der die in der Vergangenheit erzielten Fortschritte bei der öffentlichen Gesundheit infrage stellt.

Sowohl die neue Gesundheitsstrategie des Bundesrats als auch die aktuelle Covid-19-Pandemie unterstreichen die Dringlichkeit, die mit dem Begriff «One Health» gemeinten Zusammenhänge zwischen der Gesundheit von Menschen, Tieren und Umwelt zu erkennen und entsprechend zu handeln. Ärztinnen und Ärzte haben als Berufsgruppe mit dem weltweit höchsten Vertrauen der Bevölkerung eine besondere Verantwortung, sich für den Schutz und die Förderung der Gesundheit einzusetzen. Der Verband Schweizer Medi- 
zinstudierender (swimsa) hat deshalb die FMH mit Unterstützung des vsao dazu aufgefordert, ihre Verantwortung wahrzunehmen und sich im Hinblick auf den Klimawandel im Namen der Schweizer Ärzteschaft aktiv für den Schutz der öffentlichen Gesundheit einzusetzen. An der Sitzung der Delegiertenversammlung vom 3. September 2020 wurde ein entsprechender Antrag ohne Gegenstimmen gutgeheissen. Die Traktandierung in der ÄK ist erfolgt, damit diese den Beschluss der Delegiertenversammlung zur Kenntnis nehmen kann.

Nachtraktandierung: Antrag der Dachverbände SMSR, VEDAG und OMCT - Medienmitteilung zu Covid-19

Jürg Schlup / Präsident FMH leitet über zum folgenden schriftlich eingereichten Antrag der Dachverbände SMSR, VEDAG und OMCT. Diese Nachtraktandierung erfordert gemäss Artikel 31 Absatz 3 der Statuten eine qualifizierte 2/3-Mehrheit.

Antrag:

Die ÄK genehmigt den Nachtraktandierungs-Antrag, eine Medienmitteilung FMH zur aktuellen Gesundheitssituation zu verfassen.

Beschluss:

Der Antrag, welcher eine 2/3-Mehrheit benötigt, wird mit 102 Ja, 11 Nein und 3 Enthaltungen angenommen. Es folgt eine längere Diskussion zum Inhalt der Medienmitteilung, die am 30. Oktober 2020 verschickt werden soll. Die Kernbotschaft dieser Medienmitteilung soll lauten: «... deshalb fordert die Ärzteschaft die Bevölkerung auf, die Distanzregeln, die Handhygiene und die Maskenpflicht strikt einzuhalten sowie die Empfehlungen der Behörden hinsichtlich der Anzahl Kontakte gewissenhaft zu befolgen. Diese einfachen Massnahmen sind die Grundlage für eine wirksame Bekämpfung des Virus ..."

Antrag:

Die ÄK beschliesst, den ZV zu beauftragen, am 30. Oktober 2020 eine Medienmitteilung betreffend Covid-19 im Sinne der drei antragstellenden Dachgesellschaften und wie von Carlos Quinto vorgelesen, zu publizieren.

\section{Beschluss:}

Der Veröffentlichung der Medienmitteilung zu Covid-19 wird mit 125 Ja, 4 Nein und 2 Enthaltungen zugestimmt.

Zum Schluss wird von Seiten der Delegierten ein grosses Dankeschön mit Gratulation für Organisation und Durchführung der ersten virtuellen ÄK in der Geschichte der FMH an alle an der ÄK Beteiligten gerichtet.

\section{Varia}

Ursina Pally Hofmann / Generalsekretärin FMH und Leiterin Rechtsdienst informiert über die ÄK-Termine 2021/22.

\section{Termine ÄK 2021}

Donnerstag, 27. Mai 2021

Donnerstag, 28. Oktober 2021

\section{Termine ÄK 2022}

Donnerstag, 19. Mai 2022

Donnerstag, 27. Oktober 2022

Jürg Schlup / Präsident FMH bedankt sich bei den Delegierten für ihr aktives und konstruktives Mitwirken und insbesondere für ihre Unterstützung und Toleranz bei der Durchführung dieser virtuellen Sitzung Seinen Dank richtet er nochmals an die drei Technikteams vor Ort, an die Mitarbeitenden der Abteilungen Zentrales Sekretariat, Rechtsdienst und Kommunikation sowie an alle weiteren Mitarbeitenden, die bei der Organisation und Durchführung dieser zweitägigen ÄK mitgewirkt haben

Jürg Schlup / Präsident FMH schliesst die Sitzung und verabschiedet sich. Es war seine letzte ÄK, die er leiten durfte. Es war ihm ein Vergnügen, eine Freude und eine Ehre, über all die Jahre Präsident aller Ärztinnen und Ärzte der FMH sein zu dürfen. Er wünscht allen eine gute Heimkehr und beste Gesundheit. 


\section{Glossar}

\begin{tabular}{|c|c|}
\hline Abkürzung & Erläuterung \\
\hline ÄG & Ärztegesellschaft \\
\hline AGZ & ÄrzteGesellschaft des Kantons Zürich \\
\hline ÄK & Ärztekammer \\
\hline ats-tms & Tarifpartnerschaft: arzttarif Schweiz - tarif médical Suisse \\
\hline BAG & Bundesamt für Gesundheit \\
\hline BFS & Bundesamt für Statistik \\
\hline CVP & Christlichdemokratische Volkspartei \\
\hline DSG & Datenschutzgesetz \\
\hline DV & Delegiertenversammlung \\
\hline EMH & Editores Medicorum Helveticorum \\
\hline EPA & Entrustable professional acitivities \\
\hline ETH & Eidgenössisch Technische Hochschule \\
\hline FG & Fachgesellschaften \\
\hline $\mathrm{FMCH}$ & Foederatio Medicorum Chirurgicorum Helvetica \\
\hline FMH & Verbindung der Schweizer Ärztinnen und Ärzte \\
\hline FMPP & Foederatio Medicorum Psychiatricorum et Psychotherapeuticorum \\
\hline GDK & Schweizerische Gesundheitsdirektorenkonferenz \\
\hline GESKES & Gesellschaft für klinische Ernährung der Schweiz \\
\hline GEVER & Elektronische Geschäftsverwaltung \\
\hline GO & Geschäftsordnung \\
\hline GPK & Geschäftsprüfungskommission \\
\hline GS & Generalsekretariat \\
\hline $\mathrm{H}+$ & Die Spitäler Schweiz \\
\hline HIN & Health Infonet \\
\hline ICT & Informations- und Kommunikationstechnologie \\
\hline IKS & Internes Kontrollsystem \\
\hline KÄG & Kantonale Ärztegesellschaften \\
\hline KHM & Kollegium für Hausarztmedizin \\
\hline KSW & Kantonsspital Winterthur \\
\hline MAS & Medical Ambulatory - Structure \\
\hline MedBG & Medizinalberufegesetz \\
\hline MedEd & Symposium zur Weiterentwicklung der ärztlichen Weiterbildung \\
\hline mws & medical women switzerland \\
\hline NAKO & Nationale Konsolidierungsstelle \\
\hline OMCT & Ordine dei medici del canton Ticino \\
\hline PA & Physician Associate \\
\hline $\mathrm{RD}$ & Rechtsdienst \\
\hline RoKo & Rollende Kostenstudie \\
\hline SAPPM & Schweizerische Akademie für Psychosomatische und Psychosoziale Medizin \\
\hline SGC & Die Schweizer Chirurginnen und Chirurgen \\
\hline SFSM & Swiss Federation of Specialities in Medicine \\
\hline SGGG & Schweizerische Gesellschaft für Gynäkologie und Geburtshilfe \\
\hline SGNC & Schweizerische Gesellschaft für Neurochirurgie \\
\hline SGNOR & Schweizerische Gesellschaft für Notfall- und Rettungsmedizin \\
\hline SIWF & Schweizerisches Institut für ärztliche Weiter- und Fortbildung \\
\hline SMSR & Société Médicale de la Suisse Romande \\
\hline SSNPath & Swiss Society of Neuropathologie \\
\hline swimsa & Swiss Medical Students' Association \\
\hline TARDOC & Neuer Tarif Medizin für ambulante Einzelleistungen \\
\hline TX & TrustX Management AG (TMA) \\
\hline VEDAG & Verband Deutschschweizer Ärztegesellschaften \\
\hline VLSS & Verein der Leitenden Spitalärzte der Schweiz \\
\hline VSAO & Verband Schweizerische Assistenz- und Oberärzte/-innen \\
\hline VZÄ & Vollzeitäquivalente \\
\hline ZV & Zentralvorstand \\
\hline
\end{tabular}

